\title{
Mdm2 regulates cardiac contractility by inhibiting GRK2-mediated desensitization of $\beta$-adrenergic receptor signaling
}

Pierre-Yves Jean-Charles, ${ }^{1}$ Samuel Mon-Wei Yu, ${ }^{1}$ Dennis Abraham, ${ }^{1}$ Reddy Peera Kommaddi, ${ }^{1}$ Lan Mao, ${ }^{1}$ Ryan T. Strachan, ${ }^{1}$ Zhu-Shan Zhang, ${ }^{1}$ Dawn E. Bowles, ${ }^{2}$ Leigh Brian, ${ }^{1}$ Jonathan A. Stiber, Stephen N. Jones, ${ }^{3}$ Walter J. Koch, ${ }^{4}$ Howard A. Rockman, ${ }^{1,5,6}$ and Sudha K. Shenoy,

'Department of Medicine, Division of Cardiology, and 'Department of Surgery, Duke University Medical Center, Durham, North Carolina, USA. ${ }^{3}$ Department of Cell and Developmental Biology, University of Massachusetts Medical School, Worcester, Massachusetts, USA. ${ }^{4}$ Center for Translational Medicine, Department of Pharmacology, Temple University School of Medicine, Philadelphia, Pennsylvania, USA. ${ }^{5}$ Department of Cell Biology, and ${ }^{6}$ Department of Molecular Genetics, Duke University Medical Center, Durham, North Carolina, USA.

The oncoprotein Mdm2 is a RING domain-containing E3 ubiquitin ligase that ubiquitinates $G$ protein-coupled receptor kinase 2 (GRK2) and $\beta$-arrestin2, thereby regulating $\beta$-adrenergic receptor ( $\beta A R$ ) signaling and endocytosis. Previous studies showed that cardiac Mdm2 expression is critical for controlling $\mathrm{p} 53$-dependent apoptosis during early embryonic development, but the role of $\mathrm{Mdm} 2$ in the developed adult heart is unknown. We aimed to identify if Mdm2 affects $\beta A R$ signaling and cardiac function in adult mice. Using Mdm2/p53-KO mice, which survive for 9-12 months, we identified a critical and potentially novel role for Mdm2 in the adult mouse heart through its regulation of cardiac $\beta 1 A R$ signaling. While baseline cardiac function was mostly similar in both Mdm2/p53-KO and wild-type (WT) mice, isoproterenol-induced cardiac contractility in Mdm2/p53-KO was significantly blunted compared with WT mice. Isoproterenol increased cAMP in left ventricles of WT but not of Mdm2/p53-KO mice. Additionally, while basal and forskolin-induced calcium handling in isolated Mdm2/p53-KO and WT cardiomyocytes were equivalent, isoproterenol-induced calcium handling in $\mathrm{Mdm2} / \mathrm{p} 53-\mathrm{KO}$ was impaired. Mdm2/p53KO hearts expressed 2-fold more GRK2 than WT. GRK2 polyubiquitination via lysine-48 linkages was significantly reduced in Mdm2/p53-KO hearts. Tamoxifen-inducible cardiomyocyte-specific deletion of Mdm2 in adult mice also led to a significant increase in CRK2, and resulted in severely impaired cardiac function, high mortality, and no detectable $\beta A R$ responsiveness. Gene delivery of either Mdm2 or CRK2-CT in vivo using adeno-associated virus 9 (AAV9) effectively rescued B1ARinduced cardiac contractility in Mdm2/p53-KO. These findings reveal a critical p53-independent physiological role of Mdm2 in adult hearts, namely, regulation of GRK2-mediated desensitization of BAR signaling.

Authorship note: P.Y. Jean-Charles and S.M.W. Yu contributed equally to this work.

Conflict of interest: The authors have declared that no conflict of interest exists.

Submitted: June 27, 2017

Accepted: July 27, 2017

Published: September 7, 2017

Reference information: JCI Insight. 2017;2(17):e95998. https://doi.org/10.1172/jci. insight. 95998.

\section{Introduction}

The $\beta$-adrenergic receptors ( $\beta$ ARs) belong to the superfamily of G protein-coupled receptors (GPCRs) and couple to the stimulatory heterotrimeric $\mathrm{G}$ proteins and increase intracellular cAMP; physiologically, $\beta$ AR activation regulates cardiac performance, vascular tone, lipid and carbohydrate metabolism, and behavior $(1,2)$. The $\beta 1 \mathrm{AR}$ accounts for approximately $80 \%$ of the total cardiac $\beta$ ARs in mouse and human ventricles, and is mainly responsible for catecholamine-induced cardiac inotropy and lusitropy (2-5). While $\beta 1 A R$ activation enhances cardiac performance, either chronic- or overstimulation of the receptor can trigger apoptotic signaling and induce cardiac hypertrophy and cardiac dysfunction (5). In failing hearts, $\beta 1 \mathrm{AR}$ signaling is attenuated from either loss of functional coupling (desensitization) or a decline in $\beta 1 \mathrm{AR}$ density (downregulation) (3). The $\beta 2 \mathrm{AR}$, which represents approximately $20 \%$ of cardiac $\beta A R s$, has a cardioprotective role during heart failure $(3,6)$. $\beta A R s$ are regulated by various mechanisms, affecting their expression, activity, and fate. Agonist-activated $\beta$ ARs are rapidly phosphorylated by GPCR kinases (GRKs) that facilitate recruitment and binding of cytosolic adaptor proteins 
A
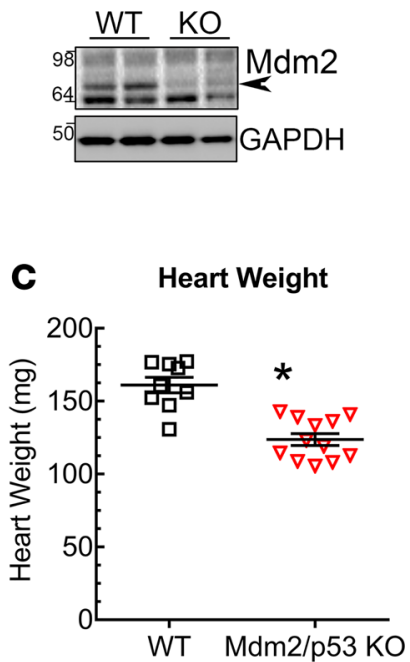

$\mathbf{E}$

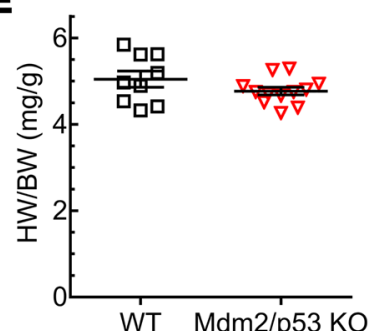

G

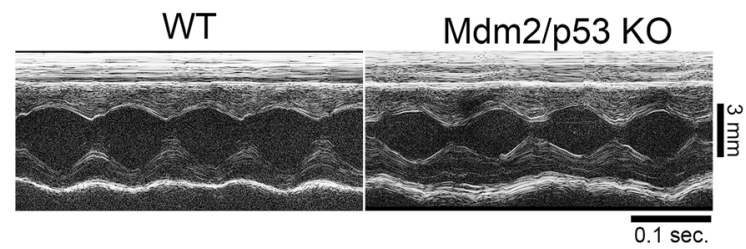

B

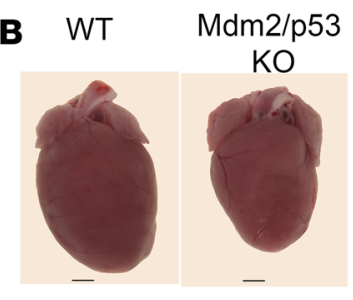

D

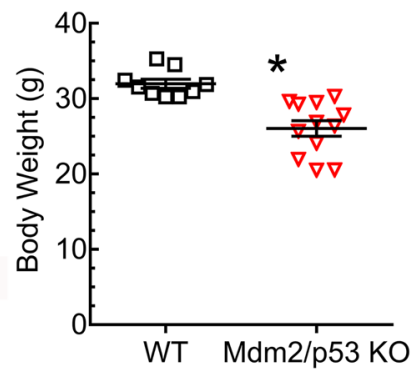

$\mathbf{F}$

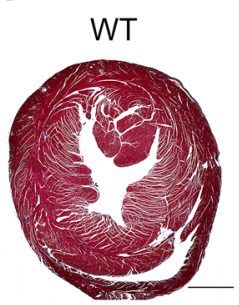

Mdm2/p53 KO

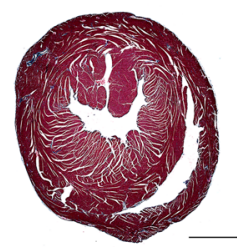

Figure 1. Cardiac morphology, histopathology, and morphometry of WT and Mdm2/p53-KO mice. (A) Immunoblot of cardiac lysates from 3- to 4-month-old WT and Mdm2/p53-KO mice with Mdm2 and GAPDH antibodies. Blot is representative of similar results obtained from greater than 10 mice of each genotype. (B) Representative whole hearts of 3- to 4-month-old WT and Mdm2/ p53-KO mice $(n=3)$. Scale bars: $1 \mathrm{~mm}$. (c) Heart weights $(\mathrm{mg})$ of 3- to 4-month-old WT $(n=9)$ and Mdm2/p53-KO $(n=12)$ mice. Error bars indicate average $\pm \mathrm{SEM}$. ${ }^{*} P<0.01$ versus WT; Student's $t$ test. (D) Body weights (g) of 3- to 4-month-old WT $(n=9)$ and Mdm2/p53-KO $(n=12)$ mice. Error bars indicate average \pm SEM. ${ }^{*} P<0.01$ versus WT; Student's $t$ test. (E) Heart weight/body weight (HW/BW) ratio calculated from data shown in C and $\mathbf{D} . P=0.17$, Student's $t$ test. (F) Representative Masson's trichrome staining of cardiac sections from of 3- to 4-month-old WT and Mdm2/p53-KO $(n=5)$. Scale bars: $1 \mathrm{~mm}$. (G) Representative baseline echocardiograms via M-mode, short-axis imaging, of WT and Mdm2/p53-KO mice (see Table 1 for ECHO analyses).

$\beta$-arrestin 1 and $\beta$-arrestin2 $(7,8)$. $\beta$-Arrestins and GRKs have dual roles in GPCR signaling: (a) they desensitize signaling by blocking $\mathrm{G}$ protein coupling and (b) they promote signaling that is independent of $G$ protein coupling by binding and activating various kinases $(7,8)$.

The $\beta 2 \mathrm{AR}, \mathrm{GRK} 2$, and $\beta$-arrestin 2 are also regulated by the posttranslational modification ubiquitination and in each case, the ubiquitinated species is linked with a distinct functional consequence $(9,10)$. Activated $\beta 2 \mathrm{AR}$ is ubiquitinated in a $\beta$-arrestin2-dependent manner by the HECT-domain E3 ubiquitin ligase NEDD4 and this posttranslational modification acts as a signal that directs the intracellular trafficking of internalized $\beta 2 \mathrm{AR}$ to the lysosomes $(9,11-15)$. On the other hand, both $\beta$-arrestin2 and GRK2 are ubiquitinated by the RING-domain E3 ubiquitin ligase mouse double minute 2 (Mdm2) $(10,16$, 17). Ubiquitinated $\beta$-arrestin 2 forms a tight complex with activated GPCRs, with the endocytic adaptor clathrin as well as with signaling kinases, thus enabling GPCR signaling in endosomal vesicles (18). Mdm2-mediated GRK2 ubiquitination leads to GRK2 degradation by $26 \mathrm{~S}$ proteasomes, which may restore $\mathrm{G}$ protein coupling at the $\beta \mathrm{AR}(10,19)$. Unfortunately, the physiological effects of Mdm2 in $\beta A R$ signaling are unknown because most of the signaling assays linking Mdm2 to the $\beta A R$ were ascertained in cell-based systems.

$\mathrm{Mdm} 2$ is an oncogene that functions as a key negative regulator of the transcription factor and tumor-suppressor protein p53 (20, 21). In normal adult cells, p53 and Mdm2 are regulated by an autoregulatory feedback loop in which activated p53 promotes Mdm2 transcription and in turn, Mdm2 inhibits $\mathrm{p} 53$ by effecting degradation of $\mathrm{p} 53$ via ubiquitination $(22,23)$. The genetic deletion of $\mathrm{Mdm} 2$ in mice causes early embryonic lethality mainly because of overactive p53 and resulting cell growth arrest and apoptosis in the embryo $(24,25)$. Accordingly, the concomitant deletion of Mdm2 and p53 rescues the lethal phenotype and the mice survive normally until 6 to 7 months of age, beyond which they are prone to developing tumors (26). Tissue-specific deletion of $\mathrm{Mdm} 2$ in cardiomyocytes leads to impaired heart development and embryonic lethality, which is also rescued by simultaneous p53 deletion (27). While these studies have established the importance of Mdm2 expression and its link with $\mathrm{p} 53$ in the embryonic heart, the function(s) of $\mathrm{Mdm} 2$ in the adult heart remains undefined. Herein, by achieving a tamoxifen-inducible deletion of Mdm2 in adult cardiomyocytes, we demonstrate that $\mathrm{Mdm} 2$ is a critical factor for mice survival and cardiac function. We further use the Mdm2/ p53 double-KO mice (referred to as Mdm2/p53-KO henceforward), which live through adulthood and adeno-associated virus-mediated (AAV-mediated) gene rescue of $\mathrm{Mdm} 2$ to define physiological role(s) of $\mathrm{Mdm} 2$ in the heart. 
Table 1. Echocardiographic measurements in WT and Mdm2/p53-KO

\begin{tabular}{lcc}
\hline & Wild Type & Mdm2/p53-KO \\
& $n=9$ & $n=12$ \\
IVS;d (mm) & $1.3 \pm 0.2$ & $1.0 \pm 0.2^{\mathrm{A}}$ \\
LVID;d (mm) & $3.5 \pm 0.1$ & $2.9 \pm 0.3^{\mathrm{A}}$ \\
LVID;s (mm) & $1.6 \pm 0.1$ & $1.1 \pm 0.3^{\mathrm{A}}$ \\
LVPW;d (mm) & $1.0 \pm 0.1$ & $1.0 \pm 0.2$ \\
FS (\%) & $53.6 \pm 2.8$ & $61.2 \pm 7.2^{\mathrm{A}}$ \\
LV Mass (Corrected) (mg) & $121.4 \pm 19.3$ & $81.8 \pm 14.9^{\mathrm{A}}$ \\
HR PW Doppler Mode (BPM) & $485.0 \pm 119.0$ & $652.0 \pm 71^{\mathrm{A}}$ \\
mVcf & $1,239.7 \pm 114.2$ & $1,675.1 \pm 265.9^{\mathrm{A}}$ \\
mVcfc & $404.7 \pm 29.9$ & $513.5 \pm 90.6^{\mathrm{A}}$ \\
BW (g) & $32.0 \pm 1.8$ & $26.1 \pm 3.6^{\mathrm{A}}$
\end{tabular}

Values are expressed as mean $\pm S D$. LV, left ventricle; s, systole; d, diastole; IVS, intraventricular septum; LVID, left ventricle internal dimension; LVPW, left ventricular posterior wall; $F S$, fractional shortening of $L V ; H R$, heart rate; $B P M$, beats per minute; $m V c f$, mean velocity of circumferential fiber shortening; mVcfc, mean velocity of circumferential fiber shortening corrected for heart rate; $\mathrm{BW}$, body weight. Statistical significance was determined by Student's $t$ test. ${ }^{A} P<0.05$ versus WT.

\section{Results}

Baseline characteristics and function of $\mathrm{Mdm} 2 / \mathrm{p} 53-\mathrm{KO}$ mice hearts. We compared age- and gender-matched $\mathrm{Mdm} 2 / \mathrm{p} 53-\mathrm{KO}$ and WT mice for overall cardiac morphology, histopathology, and function (Figure 1, A-G). Mdm2/p53-KO mice had smaller hearts as well as body sizes when compared with WT mice (Figure $1, \mathrm{~B}-\mathrm{D})$; the heart weight/body weight (HW/BW) ratio of $\mathrm{Mdm} 2 / \mathrm{p} 53-\mathrm{KO}$ was not significantly different from that of the WT mice (Figure 1E). Moreover, histochemical analyses of cross sections of the hearts showed no significant histopathology as assessed by Masson's trichrome staining (Figure 1F). Next, we assessed the cardiac function via echocardiography performed on conscious mice (Figure 1G and Table 1). M-mode echocardiography revealed no difference in the thickness of left ventricular posterior wall. The estimated left ventricle (LV) mass was significantly smaller in the $\mathrm{Mdm} 2 / \mathrm{p} 53-\mathrm{KO}$ mice compared with the WT, largely driven by a relative reduction in cardiac dimensions in the $\mathrm{Mdm} 2 / \mathrm{p} 53-\mathrm{KO}$ mice compared with WT, mirroring gross estimations of smaller Mdm2/p53-KO heart size. Notably, nonanesthetized $\mathrm{Mdm} 2 / \mathrm{p} 53-\mathrm{KO}$ mice had enhanced heart rates and fractional shortening by echocardiography (Table 1), which was lost in anesthetized $\mathrm{Mdm} 2 / \mathrm{p} 53-\mathrm{KO}$ mice undergoing invasive hemodynamic analyses (Table 2 and Supplemental Table 1; supplemental material available online with this article; https://doi.org/10.1172/jci.insight.95998DS1). These invasive studies showed nonsignificant increase in cardiac stiffness (as measured by the end-diastolic pressure-volume relationship) and similar myocardial contractility (as measured by the end-systolic pressure-volume relationship and maximal elastance) in Mdm2/p53-KO hearts compared with WT hearts under basal conditions.

Effect of isoproterenol on hemodynamics in WT and Mdm2/p53-KO mice. To determine the effect of $\beta \mathrm{AR}$ agonist stimulation on the contractile function in $\mathrm{Mdm} 2 / \mathrm{p} 53-\mathrm{KO}$ mice hearts, we performed hemodynamic measurements before and after isoproterenol stimulation. LV systolic function at baseline as assessed by $\mathrm{dP} / \mathrm{dt}_{\max }$ was not significantly different in $\mathrm{Mdm} 2 / \mathrm{p} 53-\mathrm{KO}$ mice compared with WT (Figure 2A). However, isoproterenol infusion resulted in a significantly blunted $\mathrm{LV} \mathrm{dP} / \mathrm{dt}_{\max }$ response in the $\mathrm{Mdm} 2 / \mathrm{p} 53-\mathrm{KO}$ compared with WT mice (Figure $2 \mathrm{~A}$ ). LV diastolic function measured by $\mathrm{dP} / \mathrm{dt}_{\min }$ showed significantly decreased responsiveness at baseline as well as with isoproterenol in Mdm2/p53-KO compared with WT mice (Figure 2B). Isoproterenol infusion induced similar effects on heart rate as well as systolic pressure in both WT and Mdm2/p53-KO mice, although the KO mice had significantly lower systolic pressure than WT at baseline (Supplemental Figure 1). Overall, agonist stimulation of cardiac $\beta$ ARs in the Mdm2/p53KO showed a phenotype of marked $\beta A R$ desensitization.

To ascertain whether the defects in $\beta A R$-induced cardiac performance are due to loss of Mdm2 expression that is independent of p53 deletion, we undertook an Mdm2 gene rescue approach using systemic transduction with AAV9 vectors, which produce substantial expression of target genes in cardiomyocytes in addition to other tissues such as liver and lungs (28-32). We assessed $\beta \mathrm{AR}$ responsiveness in $\mathrm{Mdm} 2 / \mathrm{p} 53-\mathrm{KO}$ mice by invasive hemodynamics in control AAV9-GFP (GFP-rescue) and AAV9-Mdm2 (Mdm2-rescue) injected mice 21 days after AAV administration. We detected recovery of Mdm2 expression in the LV by Western blotting (Supplemental Figure 2). Administration of AAV9-Mdm2 restored isoproterenol responsiveness as measured by indices of contractility and relaxation, which were not induced in $\mathrm{Mdm} 2 / \mathrm{p} 53-\mathrm{KO}$ hearts that received AAV9-GFP (Supplemental Figure 2). At the maximal dose of isoproterenol, $\mathrm{dP}^{\mathrm{d}} \mathrm{dt}_{\max }$ and $\mathrm{dP} / \mathrm{dt}_{\min }$ in mice with AAV9-Mdm2 rescue corresponded to greater than $90 \%$ and greater than $75 \%$, respectively, of signals observed in control mice, whereas GFP rescue was less than $60 \%$ of WT for both parameters (Supplemental Figure 2 and data not shown). These results showing rescue of $\beta A R$ function by AAV9-Mdm2 gene therapy strongly suggest a physiological role for $\mathrm{Mdm} 2$ in mediating catecholamine-induced cardiac contractility.

Cardiac $\beta A R$ expression and signaling in Mdm2/p53-KO mice. Although in previous studies Mdm2 expression had no direct correlation with $\beta 2 \mathrm{AR}$ downregulation in cellular assays (9), the above lack of $\beta \mathrm{AR}$ responsiveness in $\mathrm{Mdm} 2 / \mathrm{p} 53-\mathrm{KO}$ could be due to a decrease in $\beta \mathrm{AR}$ expression in the myocardium. Based on the 
Table 2. Baseline load-dependent hemodynamics

\begin{tabular}{|c|c|c|}
\hline & Wild Type & Mdm2/p53-KO \\
\hline & $n=5$ & $n=6$ \\
\hline Heart Rate (BPM) & $463 \pm 24$ & $434 \pm 84$ \\
\hline LVESP (mmHg) & $110.8 \pm 22.4$ & $90.3 \pm 30.8$ \\
\hline LVEDP (mmHg) & $2.4 \pm 1.2$ & $4.4 \pm 3.7$ \\
\hline Arterial Elastance $(\mathrm{mmHg} / \mu \mathrm{l})$ & $7.5 \pm 1.7$ & $5.7 \pm 2.8$ \\
\hline $\operatorname{Ves}(\mu \mathrm{l})$ & $16.3 \pm 4.8$ & $13.3 \pm 9.7$ \\
\hline $\operatorname{Ved}(\mu \mathrm{l})$ & $27.6 \pm 6$ & $25.6 \pm 7.1$ \\
\hline \multicolumn{3}{|l|}{ Systolic Function Parameters } \\
\hline Stroke Volume $(\mu \mathrm{l})$ & $15.3 \pm 4.2$ & $16.7 \pm 2.7$ \\
\hline Ejection Fraction (\%) & $51.5 \pm 9.9$ & $62.6 \pm 19.2$ \\
\hline Cardiac Output ( $\mu \mathrm{l} / \mathrm{min})$ & $7,129.9 \pm 2,061.1$ & $7,349.6 \pm 2,228.6$ \\
\hline Stroke Work $(\mathrm{mmHg} \times \mu \mathrm{l})$ & $1,469.6 \pm 622.8$ & $1,247.2 \pm 214.0$ \\
\hline $\mathrm{dP} / \mathrm{dt}_{\max }(\mathrm{mmHg} / \mathrm{s})$ & $8,356.4 \pm 1,333.6$ & $7,247.7 \pm 1,127.6$ \\
\hline \multicolumn{3}{|l|}{ Diastolic Function Parameters } \\
\hline $\mathrm{dP} / \mathrm{dt}_{\min }(\mathrm{mmHg} / \mathrm{s})$ & $-8,056.0 \pm 1,247.5$ & $-6,003.5 \pm 1,024.1^{A}$ \\
\hline Tau (ms) (Weiss) & $7.6 \pm 0.9$ & $7.4 \pm 1.1$ \\
\hline Tau (ms) (Glantz) & $12.6 \pm 1.8$ & $12.3 \pm 2.1$ \\
\hline \multicolumn{3}{|c|}{$\begin{array}{l}\text { Values are expressed as mean } \pm \mathrm{SD} \text {. }{ }^{A} P<0.05 \text { versus wild type, unpaired } \\
2 \text {-tailed Student's } t \text { test. }\end{array}$} \\
\hline
\end{tabular}

known impact of $\beta 1 \mathrm{AR}$ on cardiac function $(5,33)$, we assessed if $\beta A R$ expression levels were altered in the $\mathrm{Mdm} 2 / \mathrm{p} 53-\mathrm{KO}$ myocardial membranes. As shown in Figure $2 \mathrm{C}$, the total $\beta A R$ expression levels determined by ${ }^{125} \mathrm{I}$-cyanopindolol binding $(34,35)$ were comparable in the Mdm2/p53-KO and WT. Additionally, competition radioligand binding assays using the subtype-selective $\beta A R$ antagonists, CGP20712A ( $\beta 1 \mathrm{AR}$ specific) and ICI-118551 ( $\beta 2 \mathrm{AR}$ specific) revealed that expression levels and proportions of $\beta 1$ and $\beta 2 \mathrm{AR}$ subtypes were equivalent in the Mdm2/p53-KO and the WT (Supplemental Figure 3). Accordingly, absence of Mdm2 in adult heart does not adversely affect membrane expression of $\beta A R s$.

Next, we ascertained the signaling capacity of agonist-activated $\beta A R s$ by measuring isoproterenol-induced cAMP in LVs of $\mathrm{Mdm} 2 / \mathrm{p} 53-\mathrm{KO}$ and WT mice. While acute infusions of isoproterenol caused a significant increase in cAMP in WT mice hearts, a similar effect was not obtained in the $\mathrm{Mdm} 2 / \mathrm{p} 53-\mathrm{KO}$ mice, indicating that $\beta A R$-mediated cAMP signaling is impaired in the absence of Mdm2 (Figure 2D). We also assessed the effect of isoproterenol on L-type calcium current $\left(\mathrm{I}_{\mathrm{ca}, \mathrm{L}}\right)$ in isolated cardiomyocytes obtained from WT and $\mathrm{Mdm} 2 / \mathrm{p} 53-\mathrm{KO}$ hearts. In WT cardiomyocytes, isoproterenol increased $\mathrm{I}_{\mathrm{ca}, \mathrm{L}}$ 3-fold, whereas the calcium current was unaltered by isoproterenol in the $\mathrm{Mdm} 2 / \mathrm{p} 53-\mathrm{KO}$ cells (Figure 3, A and B). In contrast to the

blunted KO-cell response to isoproterenol, forskolin, which directly activates adenylyl cyclase, triggered identical increases in $\mathrm{I}_{\mathrm{ca}, \mathrm{L}}$ in both WT and $\mathrm{Mdm} 2 / \mathrm{p} 53-\mathrm{KO}$ cardiomyocytes (Figure 3C). Notably, there was no difference in the baseline L-type calcium channel current-voltage relationship between WT and $\mathrm{Mdm} 2 / \mathrm{p} 53-\mathrm{KO}$ cells (Figure 3, D and E). We also compared the levels of protein kinase A and phospholamban in WT and Mdm2/p53-KO hearts and found no significant change correlating with loss of Mdm2 (Supplemental Figure 4). These data suggest that the downstream signaling components that connect cAMP to the contractile machinery are mostly unperturbed in Mdm2/p53-KO mice and the defect in $\beta A R$ signaling in $\mathrm{Mdm} 2 / \mathrm{p} 53-\mathrm{KO}$ hearts is related to decreased $\mathrm{G}$ protein coupling or desensitization.

Figure 2. Mdm2/p53-KO have diminished cardiac responsiveness to $\beta A R$ stimulation, impaired cAMP response, but normal $\beta A R$ expression. Hemodynamic parameters measured in anesthetized mice are shown in panels. (A) Maximal first derivative of LV pressure (B) minimal first derivative of LV pressure. Data shown are average values \pm SEM ${ }^{*} P<0.01,2$-way ANOVA, Bonferroni posttest. $n=13$ (WT) and $n=17(\mathrm{KO})$. (C) $\beta A R$ density $\left(\mathrm{B}_{\max } ;\right.$ mean $\left.\pm \mathrm{SEM}\right)$ determined by ${ }^{125}$-cyanopindolol binding in myocardial membranes from WT $(n=12)$ and Mdm2/p53-KO $(n=10)$ mice. (D) cAMP production in 3-month-old WT and Mdm2/ p53-KO hearts, following acute saline or isoproterenol (ISO) infusion. ${ }^{*} P<0.05,1$-way ANOVA, Bonferroni posttest.

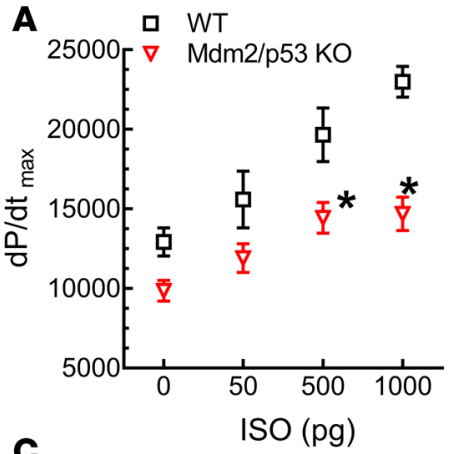

C
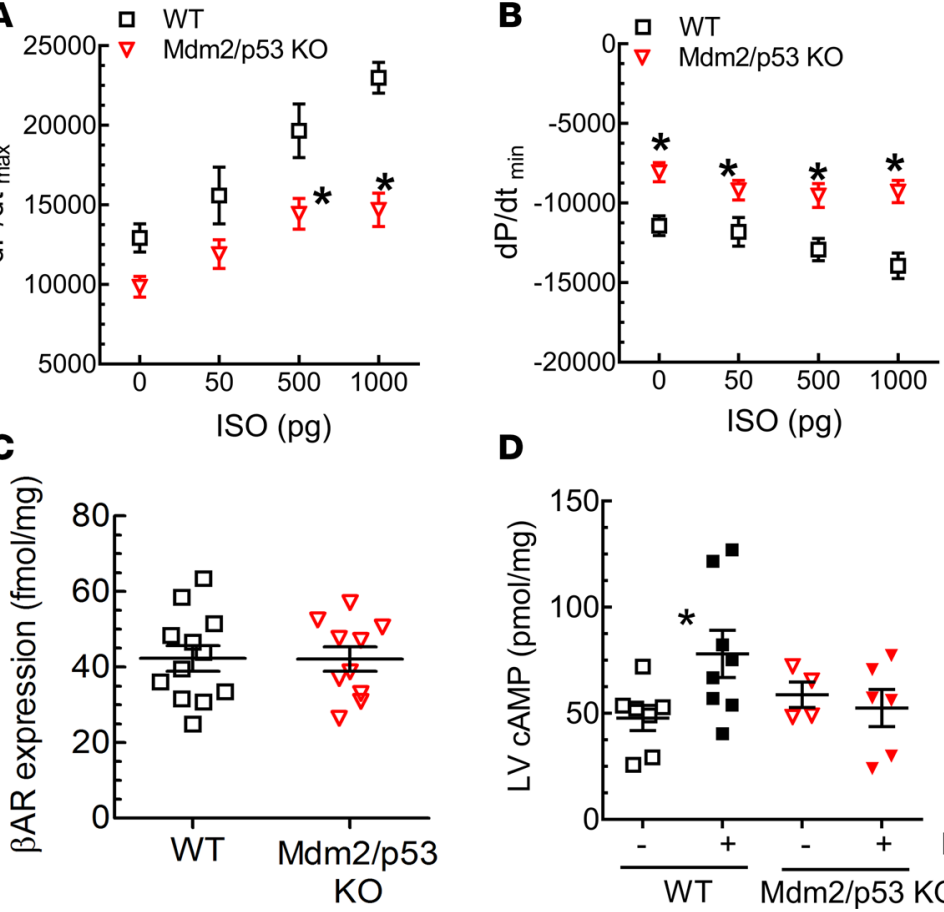
Table 3. Echocardiographic measurements before and after tamoxifen treatment in mice

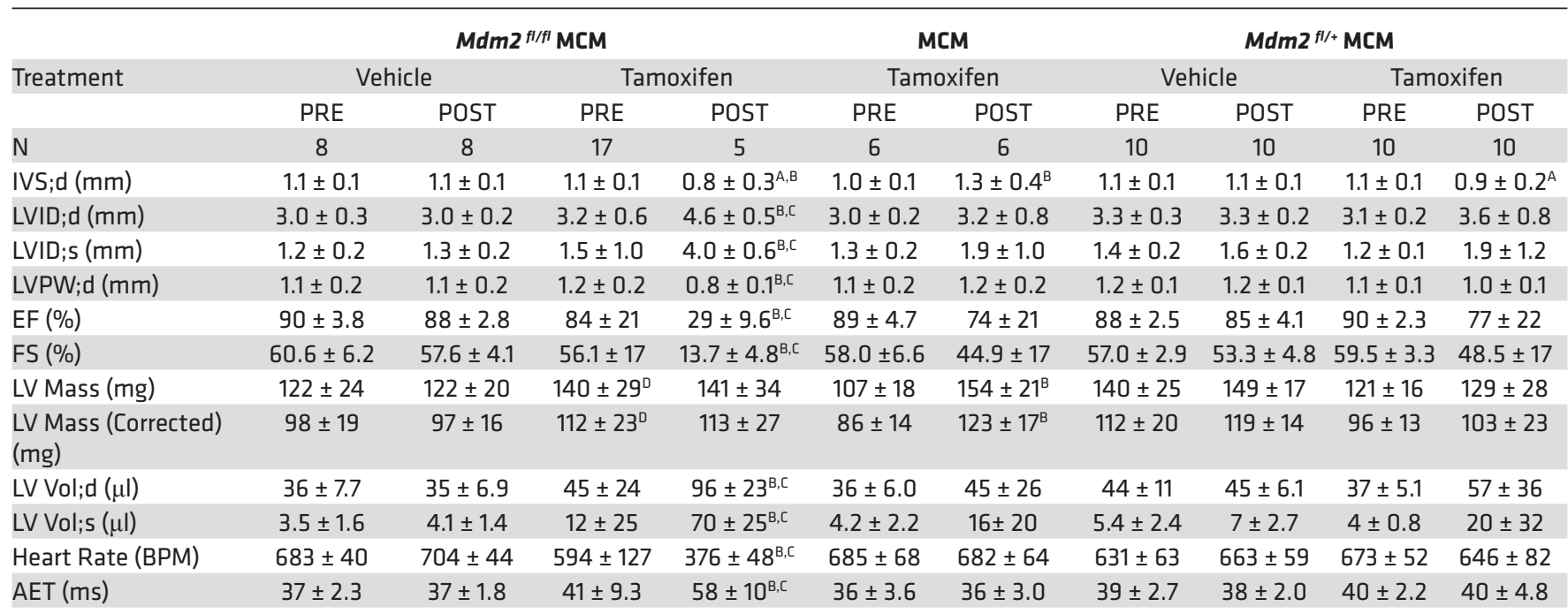

Values are expressed as mean $\pm \mathrm{SD}$. Abbreviations are as in Table 1. Vol, volume; AET, aortic ejection time. Statistical significance was determined by ANOVA. ${ }^{A} P<0.05$ versus 1 -week tamoxifen-treated MCM; ${ }^{\mathrm{B}} P<0.05$ versus pretreated group of the same genotype; ${ }^{\mathrm{C}} P<0.05$ versus all posttreated groups; ${ }^{D} P<0.05$ versus MCM before tamoxifen.

Expression levels of $\beta$-arrestins and GRK2 in Mdm2/p53-KO hearts. The reduction in cAMP levels in the $\mathrm{Mdm} 2 / \mathrm{p} 53-\mathrm{KO}$ hearts could result from aberrant receptor desensitization attributed to altered GRK and/ or $\beta$-arrestin expression. Mdm2 ubiquitinates $\beta$-arrestin1 and $-2(9,36)$; however, this ubiquitination affects $\beta$-arrestin's signaling and endocytic functions rather than promoting $\beta$-arrestin degradation (37). Additionally, $\beta$-arrestin1-KO mice have diminished $\beta A R$ desensitization (38), suggesting a direct link between $\beta A R$ desensitization and $\beta$-arrestin expression levels. Through its E3 ubiquitin ligase activity, Mdm2 promotes proteasomal degradation of GRK2 via both $\beta$-arrestin-dependent and $\beta$-arrestin-independent mechanisms (10). Hence, absence of Mdm2 could result in decreased GRK2 protein turnover and subsequent increase in GRK2 protein expression in the heart. Increase in GRK2 expression has been previously correlated with impaired contractile response by studies performed using GRK2-transgenic and conditional GRK2-KO mice (39-42). Therefore, we analyzed $\beta$-arrestin and GRK2 levels in WT and Mdm2/p53-KO cardiac lysates by immunoblotting with anti- $\beta$-arrestin and anti-GRK2 antibodies (Figure 4). While the expression levels of $\beta$-arrestin 1 and $\beta$-arrestin2 in the Mdm2/p53-KO heart were not significantly different when compared with WT hearts, the expression level of GRK2 was increased 2-fold (Figure 4). These data suggest that Mdm2 regulates GRK2 protein levels in the heart and thus facilitates the desensitization/resensitization cycles of $\beta A R$ signaling in the heart.

We hypothesized that Mdm2 promotes ubiquitin-dependent degradation of GRK2 in the heart and thus acts as a rheostat that prevents sustained desensitization of $\beta A R$ signaling by controlling GRK2 activity in the cardiomyocyte. Protein ubiquitination that involves lysine-48 polyubiquitin chains has been established as a degradation signal that is recognized by $26 \mathrm{~S}$ proteasomal machinery (43). To determine if Mdm2 mediates lysine-48 polyubiquitination of GRK2 in the heart, we used complementary approaches. We utilized a recently developed affinity matrix called tandem ubiquitin-binding entities (TUBEs), which has a 1,000-fold greater affinity for polyubiquitinated substrates than nonpolymerized ubiquitin (44-46), to pull down endogenously ubiquitinated proteins from cardiac extracts and probed the isolated proteins for GRK2 (Figure 5, $\mathrm{A}$ and $\mathrm{B})$. The TUBEs have been used successfully for capturing polyubiquitinated species of endogenously expressed proteins in cultured mammalian cells in the absence of proteasomal and/or deubiquitinase inhibitors (44-46). The TUBEs pulldown from cardiac extracts prepared from Mdm2/p53-KO mice showed a 2- to 3-fold reduction in GRK2 compared with the TUBEs pulldown from WT heart extracts (Figure 5, A and B). These results demonstrate that GRK2 polyubiquitination is reduced in the absence of Mdm2. Next, to determine if GRK2 polyubiquitination is lysine- 48 linked and if this is effected by Mdm2, we immunoprecipitated GRK2 from cardiac extracts prepared from WT and Mdm2/p53-KO mice and probed the immunoprecipitates with an IgG that specifically detects lysine-48 polyubiquitin (Figure 5, C and D). While the 
A
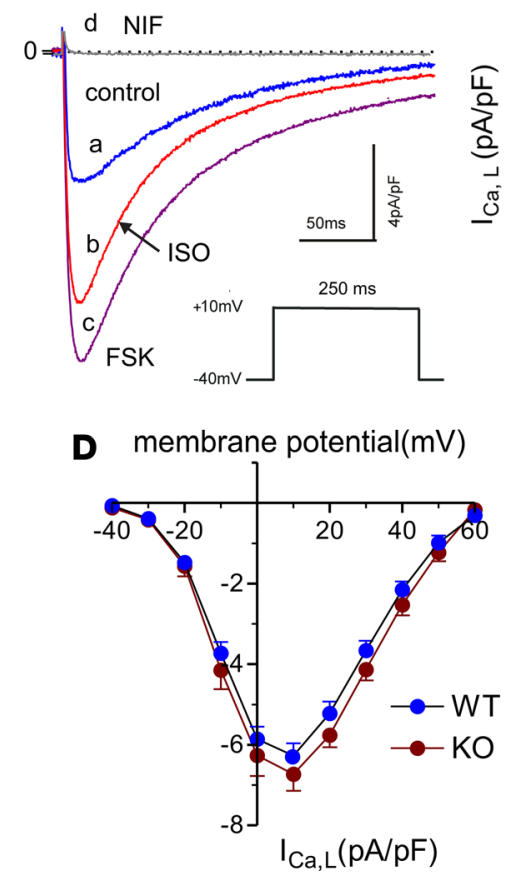
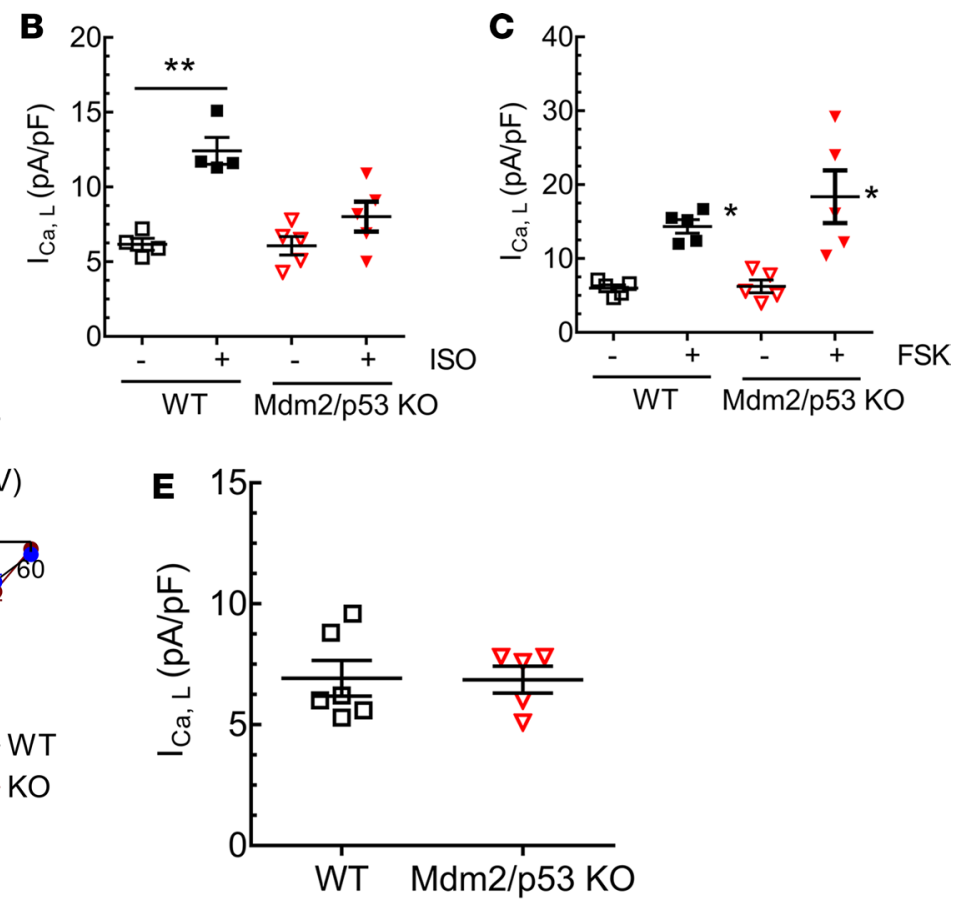

Figure 3. $\beta A R$-stimulated $\mathrm{Ca}^{2+}$ currents are impaired in Mdm2/p53-KO cardiomyocytes. (A) Representative traces of $\mathrm{I}_{\mathrm{Ca}, \mathrm{L}}$ recorded from a WT cardiomyocyte. The current was significantly enhanced by isoproterenol (ISO; $10^{-6} \mathrm{M}, \mathrm{b}$, in red) and by forskolin (FSK; $10^{-5} \mathrm{M}$, c, in purple); and also blocked by nifedipine (NIF; $5 \mu \mathrm{M}$, d, in gray). I $\mathrm{I}_{\text {ca, }}$ was elicited by a test potential of $10 \mathrm{mV}$ for $250 \mathrm{~ms}$ from a holding potential of $-40 \mathrm{mV}$ (inset). (B) ISO response of peak I in myocytes of WT and KO mice (pooled data from myocytes isolated from $n=4-5$ mice of each genotype). At least 6 cardiomyocytes were analyzed per mouse. Data indicate average $\pm \mathrm{SEM} .{ }^{* *} P<0.01$, 1 -way ANOVA, Bonferroni posttest. (C) FSK response of $\mathrm{I}_{\mathrm{Ca}, \mathrm{L}}$ in myocytes of WT and KO mice (pooled data from myocytes isolated from $n=5$ mice of each genotype). ${ }^{*} P<0.05$ versus respective no forskolin (-), 1-way ANOVA, Bonferroni posttest. (D) Baseline current-voltage relationship of $\mathrm{I}_{\mathrm{Ca}, \mathrm{L}}$ in myocytes of WT (blue circles) and KO mice (purple circles). (E) Graph shows values of peak $\mathrm{I}_{\mathrm{Ca}, \mathrm{L}}$ in myocytes of WT and $\mathrm{KO}$ (pooled data from myocytes isolated from $n=5-6$ mice of each genotype).

samples from WT heart showed lysine-48 polyubiquitin signals, this was significantly decreased in samples isolated from Mdm2/p53-KO hearts. Together, these data strongly suggest that Mdm2 mediates lysine-48 chain-specific polyubiquitination of GRK2 in the heart, and GRK2 levels are upregulated in the Mdm2/ p53-KO hearts due to defective ubiquitin-dependent proteasomal degradation.

Cardiomyocyte-specific deletion of Mdm2 in adult mice also affects GRK2 levels and $\beta A R$ responsiveness. To ascertain the cardiomyocyte-specific role of $\mathrm{Mdm} 2$, we generated $M d m 2^{t / / f} \mathrm{Myh} 6-\mathrm{MerCreMer}\left(M d m 2^{f / f} \mathrm{MCM}\right)$ mice, and induced Cre recombinase-mediated deletion of Mdm2 in 8- to 12-week-old mice by administering tamoxifen (TAM) by intraperitoneal injections for 5 consecutive days $(40,47,48)$. We used the following control cohorts: (a) vehicle-injected $M d m 2^{f / f} \mathrm{MCM}$, (b) TAM-injected $M d m 2^{f / f l}$, (c) vehicle-injected MCM, and (d) TAM-injected MCM mice. Surprisingly, $75 \%$ of TAM-injected $M d m 2^{\text {fl/fl}} \mathrm{MCM}$ male mice $(n=15$ out of 20 total) and $50 \%$ of $M d m 2^{f / f} \mathrm{MCM}$ female mice ( $n=4$ out of 8 total) died within 8 to 10 days after TAM injections (Supplemental Table 2), although mostly all mice from the control groups survived normally after TAM injections. Both MCM and $M d m 2^{f / f} \mathrm{MCM}$ mice expressed 3.4-fold more $\mathrm{Mdm} 2$ protein $(P<0.01, n=$ 5; MCM versus WT) in LVs than WT and $M d m 2^{f / f l}$ mice. We confirmed the TAM-induced deletion of Mdm2 by Western blotting cardiac extracts from the mice that survived and found significant reduction in Mdm2 in TAM-injected $M d m 2^{f / f} \mathrm{MCM}$ but not in TAM-injected MCM mice (Figure 6, A-C). Because Mdm2 has been shown to regulate p53, we analyzed the TAM-treated hearts for any alteration in p53 expression. As shown in Figure 6D, a dramatic increase in p53 was observed in cardiac tissues upon deletion of Mdm2 with TAM ( $>20$-fold increase compared with WT $n=3, P<0.05$ ). We next tested if the level and cleavage of the critical apoptosis initiator caspase 3 was altered in $M d m 2^{f / f} \mathrm{MCM}$ hearts after TAM treatment. In all the TAM-treated $M d m 2^{f / f} \mathrm{MCM}$ mice, there was not only an increase in p53, but also an increase in cleaved caspase 3 (Figure $6 \mathrm{E})$. These data suggest that Mdm2 deletion initiates apoptosis in the adult cardiac myocytes, which is perhaps the major reason for the observed mortality in TAM-treated $M d m 2^{f / / f} \mathrm{MCM}$ mice.

We next determined cardiac function of $M d m 2^{f / f} \mathrm{MCM}$ at baseline and after TAM-induced Mdm2 deletion. 

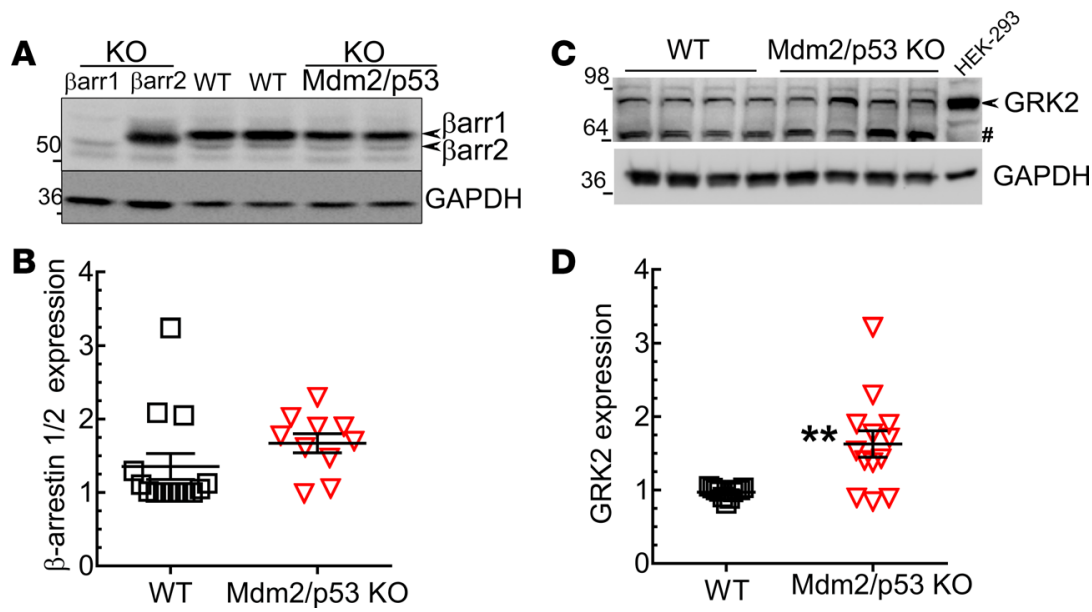

Figure 4. Expression levels of $\boldsymbol{\beta}$-arrestins and GRK2. Cardiac lysates from WT and Mdm2/p53-KO mice were immunoblotted for $\beta$-arrestins (A) and GRK2 (C). In A, cardiac lysates from $\beta$-arrestin1-KO and $\beta$-arrestin2-KO are shown for comparison. The protein extracts from these $\beta$-arrestin-KO mice (which are $[57 / B L 6$ ) have a slightly altered protein profile and hence the band mobility of $\beta$-arrestin1 is slightly different than the Mdm2/p53 and WT controls (which are B6/129 hybrids, see Methods). In each case, the membrane was reprobed for GAPDH. GRK2 IgC detected 2 bands in cardiac lysates, of which the $80-\mathrm{kDa}$ band that corresponds to GRK2 in HEK-293 cells was analyzed (\# denotes additional GRK2 isoform or nonspecific band). Densitometric quantification of protein levels (B and $\mathbf{D}$ ) from 3- to 4-month-old WT and Mdm2/p53-KO mouse hearts is plotted as protein/CAPDH ratio. Data indicate the average \pm SEM. ${ }^{* *} P<0.01$ versus WT; Student's $t$ test.

Echocardiography of conscious mice performed prior to TAM injection showed no significant impairment in the cardiac function of $M d m 2^{f / f} \mathrm{MCM}$ (Table 3). However, the $M d m 2^{f / / f} \mathrm{MCM}$ mice that survived after TAM injections exhibited severe cardiac dilation and dysfunction (Table 3 and Figure 7A). Moreover, the TAM-treated $M d m 2^{f / f} \mathrm{MCM}$ mice were unresponsive to $\beta \mathrm{AR}$ agonist stimulation, as increasing doses of isoproterenol failed to stimulate cardiac contractility (Table 3 and Figure 7, B and C), which corroborates our findings with the $\mathrm{Mdm} 2 / \mathrm{p} 53-\mathrm{KO}$. On the other hand, vehicle-injected $M d m 2^{f / f} \mathrm{MCM}$ showed minimal changes in cardiac function as measured by echocardiography (Table 3) and displayed expected increases in LV function and relaxation with increasing doses of isoproterenol (Figure 7, B and C). Mdm2 fl/fl, which have intact Mdm2, showed normal $\beta$ AR-induced cardiac inotropy and lusitropy (Figure 7, B and C). The $\beta A R$ responsiveness of vehicle-treated $M d m 2^{f / f f} \mathrm{MCM}$ was comparable to that of $M d m 2^{f / f l}$ (Figure 7, B and C). However, both untreated and TAM-treated MCM mice showed reduction in the contractile response at high doses of isoproterenol compared with $M d m 2^{f / f l}$.

Interestingly, GRK2 levels dramatically increased when Mdm2 was deleted in Mdm $2^{f / f} \mathrm{MCM}$ mice heart; however, TAM did not alter either GRK2 or Mdm2 levels in MCM mice (Figure 7, D and E). Mdm2 $2^{f / / f} \mathrm{MCM}$ was generated by crossbreeding 2 parental strains, namely, $M d m 2^{f / f l}$ and $\mathrm{MCM}$. While there are no prior studies of cardiac function of $M d m 2^{f / f l}$, previous studies of MCM have revealed defects in cardiac function (47). Nonetheless, our studies comparing these different cohorts (Figures 6 and 7, and Supplemental Tables 2 and 3) clearly show that in adult mice cardiac Mdm2 is a survival factor that regulates not only p53 expression, but also $\beta A R$ responsiveness and GRK2 expression and that loss of Mdm2 in the adult cardiomyocyte is detrimental in both male and female mice.

AAV9-GRK-CT gene delivery rescues the $\beta A R$ responsiveness in Mdm2/p53-KO mice. Previous studies with transgenic mice that overexpress either GRK2 or a C-terminal fragment of GRK2 (GRK2-CT) have revealed reciprocal effects on $\beta A R$ responsiveness in the 2 models (49). While GRK2 overexpression caused attenuation of $\beta A R$-induced contractility and reduced adenylyl cyclase coupling, GRK2-CT overexpression led to enhanced cardiac contractility (49). GRK2-CT has been further shown to act as an inhibitor of endogenous GRK2 in a variety of experimental systems ranging from cells to mice $(50,51)$. We therefore used a GRK2 CT gene expression approach to determine if inhibiting GRK2 could rescue the defective cardiac function that arises from Mdm2 deletion. Because of the high mortality observed in the TAM-induced cardiac-specific KO model, we resorted to the Mdm2/p53-KO to test the effects of GRK2-CT. We injected AAV9-GRK2-CT virus or control AAV9-GFP virus and phenotyped the mice 21 days after viral delivery. In those mice with detectable expression of GRK2-CT, we observed enhanced basal cardiac contractility as well as a robust response with isoproterenol administration compared with control GFP-expressing mice (Figure 8, A-C). 


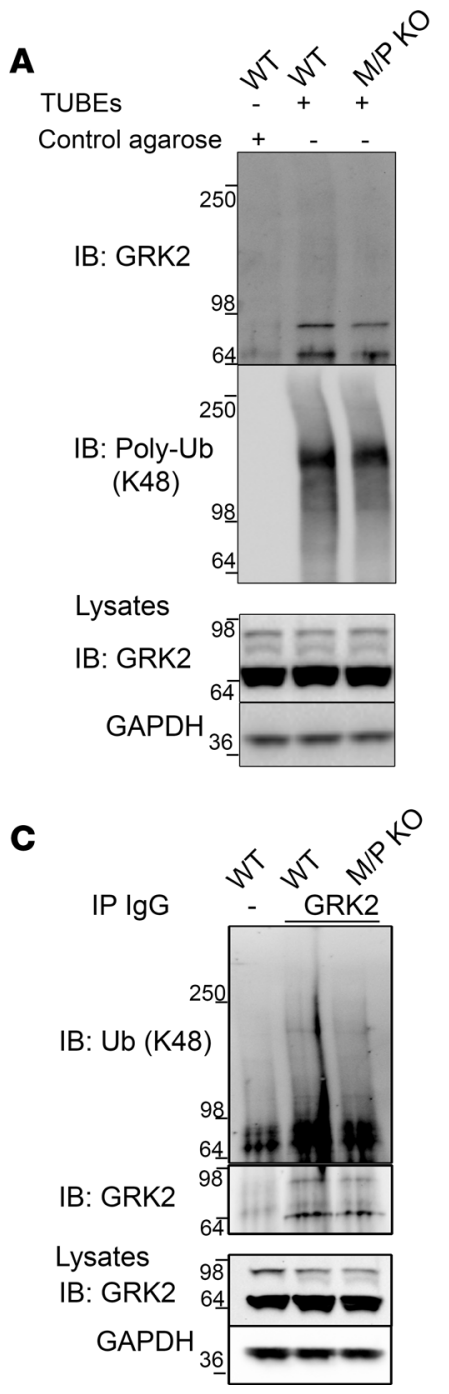

\section{B}

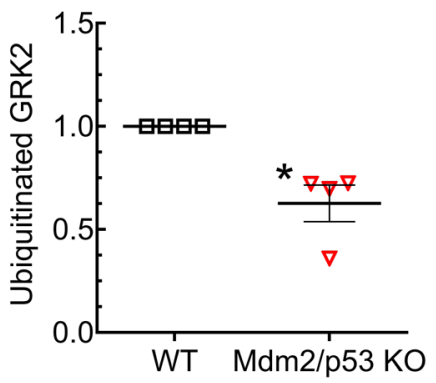

Figure 5. Lysine-48 chain-specific ubiquitination of GRK2 in WT and Mdm2/p53-KO mouse hearts. (A) TUBEs affinity pulldowns were performed on cardiac lysates from 3- to 4-month-old WT and Mdm2/ p53-KO and proteins were resolved with Tris-glycine $4 \%$ to $20 \%$ gradient gels. Immunoprecipitated (IP'd) samples were immunoblotted serially with GRK2 IgG and then with lysine-48-linked ubiquitin chain-specific IgG. Lysate samples were immunoblotted (IB) with GRK2 and GAPDH antibodies. (B) GRK2 bands in each lane were normalized to their corresponding ubiquitin smears after subtraction of the control agarose lane background. These ratios were normalized to the WT CRK2 level in the corresponding sample. Data indicate the mean $\pm S E M, n=4$ mice for each condition. ${ }^{*} P=0.029$ versus WT; Mann-Whitney test. (C) Cardiac lysates from 3- to 4-month-old WT and Mdm2/p53-KO mice were IP'd with anti-GRK2 IgG (see Methods) and proteins were resolved with Tris-glycine $4 \%$ to $12 \%$ gradient gels. IP'd samples were immunoblotted serially with lysine-48-linked ubiquitin chain-specific IgG, followed by GRK2. Lysate samples were immunoblotted for GRK2 and GAPDH. (D) Ubiquitin smears in each lane were normalized to their corresponding GRK2 band intensities after subtraction of the background from the nonspecific lgG lane. Data indicate the mean \pm SEM, $n=6$ mice for each condition. ${ }^{*} P=0.04$ versus WT; Mann-Whitney test.

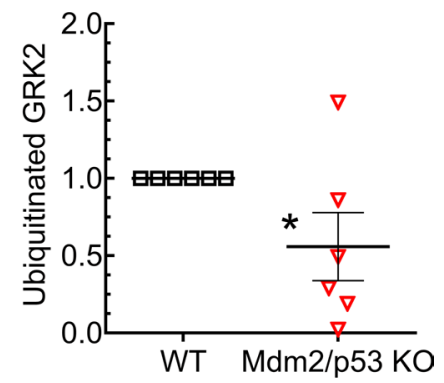

These experiments further confirm that the cardiac defects and diminished $\beta \mathrm{AR}$ responsiveness in the Mdm2/ p53-KO are attributable to an increase in GRK2 activity and GRK2-induced desensitization.

In summary, our experiments suggest that in the WT cardiomyocyte, GRK2 levels are regulated by Mdm2 via lysine-48 polyubiquitination and degradation (Figure 9). In the absence of Mdm2, GRK2 is stabilized and blocks $\beta A R-G$ protein coupling, rendering these receptors to remain in a desensitized state. Accordingly, in normal adult hearts, Mdm2 could act as a critical factor for (a) cardiomyocyte survival through regulation of p53-mediated apoptosis and (b) normal coupling of $\beta A R s$ to $G$ protein signaling, a role that is p53 independent.

\section{Discussion}

The role of Mdm2 in the adult heart has been elusive, owing to the embryonic lethality associated with global and cardiac deletions of $\operatorname{Mdm} 2(24,25,27)$. The lethal phenotype associated with $\mathrm{Mdm} 2 \mathrm{KO}$ is linked to its regulation of the proapoptotic protein $\mathrm{p} 53$, because concomitant deletion of $\mathrm{p} 53$ nullifies the early embryonic mortality $(24,25,27)$. Interestingly, overexpression of $\mathrm{Mdm} 2$ in isolated cardiomyocytes results in not only p53 downregulation but also decreased hypoxia/reoxygenation-induced cell death and reduction of $\alpha$-agonist-induced cardiac hypertrophy (52). On the other hand, p53 has been correlated with the development of cardiac hypertrophy in response to pressure overload and increased mortality after myocardial infarction by inhibiting cardiac angiogenesis $(53,54)$. p53 is upregulated in human heart failure $(55,56)$ and causes adverse effects, whereas Mdm2 is cardioprotective despite its oncogenic properties.

Herein we report that the expression of $\mathrm{Mdm} 2$ in the adult mouse heart is essential for survival and that the ablation of $\mathrm{Mdm} 2$ in adult cardiomyocytes causes severe cardiac dysfunction. Our studies show 

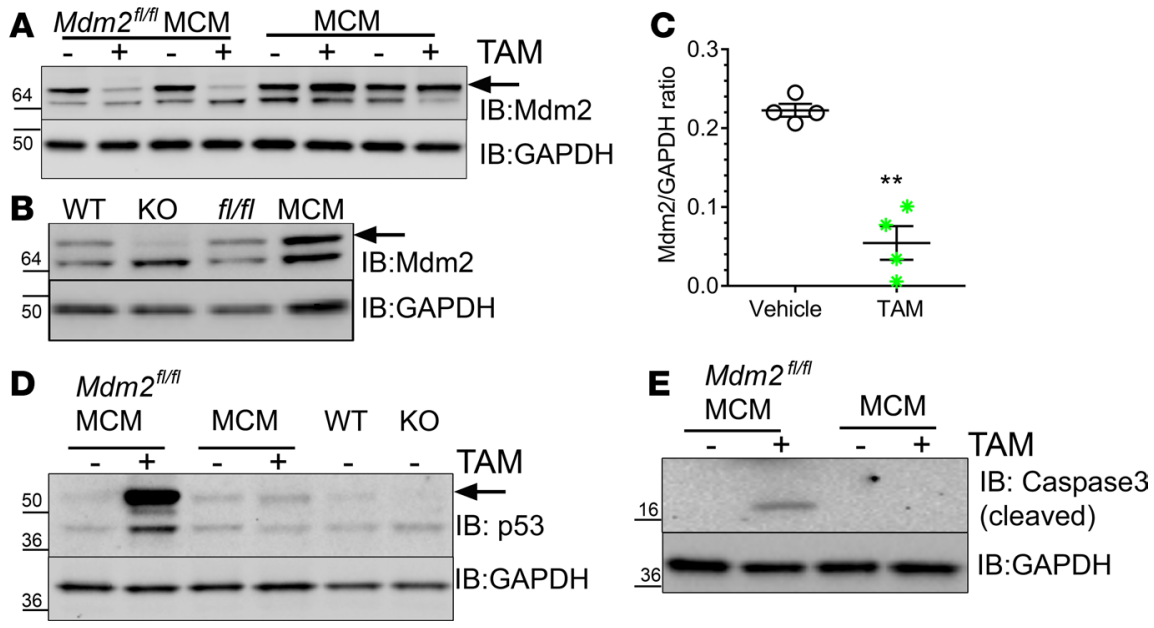

Figure 6. Effects of tamoxifen-induced conditional deletion of $\mathbf{M d m 2}$ in the mouse heart. (A) Immunoblots of LV extracts of $M d m 2^{f / / 7} M e r C r e M e r(M C M)$ and MCM mice after 1 week of tamoxifen (TAM) or vehicle treatment. (B) Immunoblot of WT, Mdm2/p53-KO, Mdm2 fl/fil, and MCM ventricular extracts; all the immunoblots in $\mathbf{A}$ and $\mathbf{B}$ were serially probed with $\mathrm{Mdm} 2$ and GAPDH antibodies. (C) The graph summarizes quantification of Mdm2 bands in the hearts of vehicle-treated and TAM-treated Mdm2 $2^{f / f} \mathrm{MCM}$ mice. ${ }^{* *} P=0.0003$, Student's $t$ test. Cardiac extracts from Mdm2 $2^{f / f} \mathrm{MerCreMer}$ (MCM) and MCM were immunoblotted for $\mathrm{p} 53$ (D) and cleaved caspase 3, 17-kDa fragment (E); samples from $n=3$ mice were analyzed for each condition.

that $\mathrm{Mdm} 2$ is critical for cardiac responsiveness to $\beta A R$ stimulation and this effect of $\mathrm{Mdm} 2$ is independent of p53. However, the severe cardiac phenotype that we observe after TAM-induced deletion of Mdm2 in adult mice could be due to multiple damaging effects separate from Mdm2's role in $\beta A R$ signaling. These effects may involve transient cardiomyopathy observed in the MCM mice with TAM treatment (47, 57-59), an increase in p53-dependent caspase activation $(60,61)$, and cardiomyocyte apoptosis upon deletion of Mdm2 (27), in addition to other mechanisms that remain to be identified.

Cell-based assays previously linked Mdm2 with $\beta$-arrestin and GRK2, which are important modulators of $\beta A R$ signaling $(37,62)$. Mdm2-dependent ubiquitination of the multifunctional adaptor $\beta$-arrestin enhances the scaffolding ability of $\beta$-arrestin, promoting stable $\beta$-arrestin interaction with the activated receptor, recruitment of components of the endocytic machinery, and receptor internalization as well as signaling in endosomes via kinase scaffolding (37). On the other hand, Mdm2-mediated ubiquitination of GRK2, which occurs in a $\beta$-arrestin-independent manner in nonstimulated cells and via $\beta$-arrestin scaffolding upon agonist stimulation of the $\beta A R$, targets GRK2 for proteasomal degradation, promoting signal resensitization (62).

By using 2 distinct models of $\mathrm{Mdm} 2 \mathrm{KO}$, we demonstrate that Mdm2 expression is critical for normal $\beta 1 A R$-induced cardiac contractility. The blunted cardiac responsiveness was not due to downregulation of the $\beta A R$, as we observed no difference in the cardiac $\beta A R$ subtype expression in the mouse ventricles. Moreover, Mdm2 deletion did not affect expression of either $\beta$-arrestin isoform, which is consistent with the role of $\mathrm{Mdm} 2$ in regulating the functions of $\beta$-arrestin rather than targeting $\beta$-arrestin for proteasomal degradation. On the other hand, both conditional deletion of $\mathrm{Mdm} 2$ in adult heart and its deletion in $\mathrm{Mdm} 2 / \mathrm{p} 53-\mathrm{KO}$ mice lead to the upregulation of GRK2. Our findings also reveal that Mdm2 regulates basal cardiac GRK2 levels by promoting GRK2 lysine-48 polyubiquitination that targets proteins for rapid degradation via 26S proteasomes. Importantly, adenoviral rescue of Mdm2 or inhibition of GRK2 in Mdm2/p53 hearts restores $\beta A R$-induced cardiac responsiveness. Hence, the effects of Mdm2 on GRK2 turnover as well as $\beta A R$-induced contractility are independent of the established Mdm2-p53 regulatory loop.

In heart failure, dysregulation of $\beta A R$ signaling is associated with myocyte apoptosis, cardiac remodeling and dysfunction as well as death (63). GRK2 expression is also elevated in heart failure; while this may serve as a compensatory mechanism at the initial stage of the disease, upregulation of GRK2 in heart failure worsens cardiac function $(64,65)$. GRK2-CT that inhibits GRK2 activity improves cardiac function in various heart disease models that include myocardial infarction, cardiac hypertrophy, and heart failure (50). Inhibition of GRK2 activity by GRK2-CT restores $\beta$ AR-induced cardiac contractility caused by the absence of Mdm2, confirming that Mdm2-mediated regulation of GRK2 is necessary for 
A
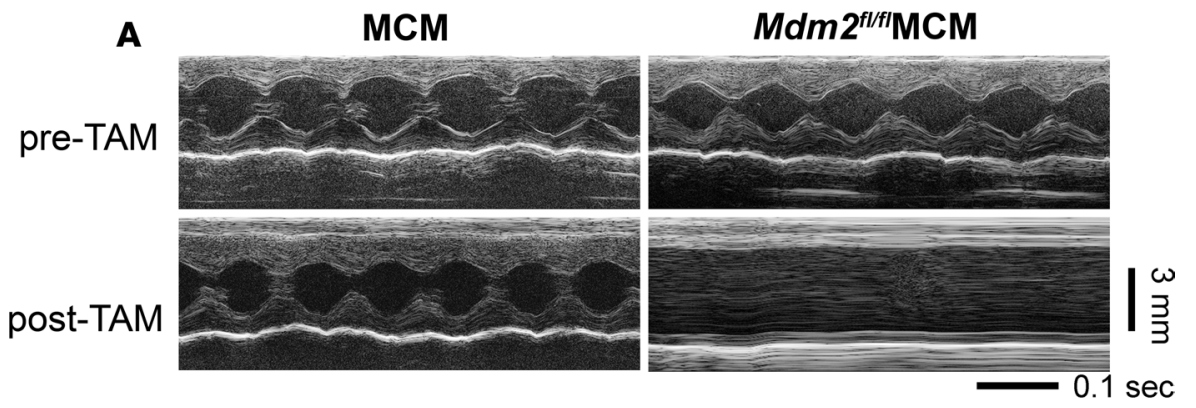

B

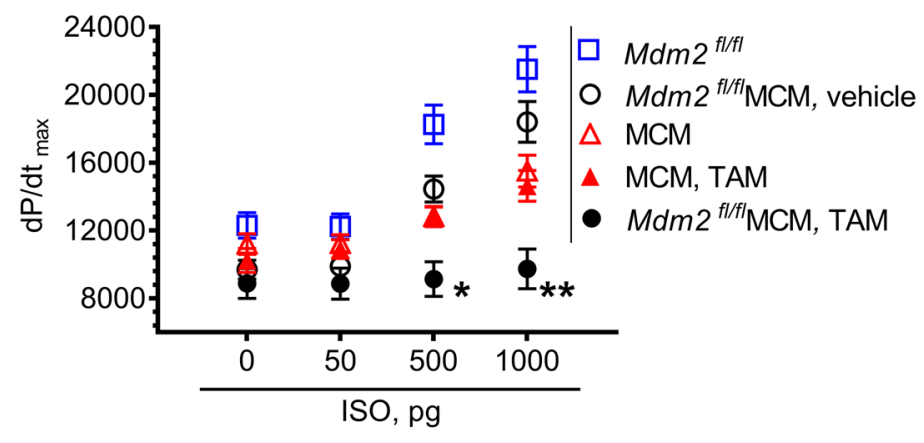

C

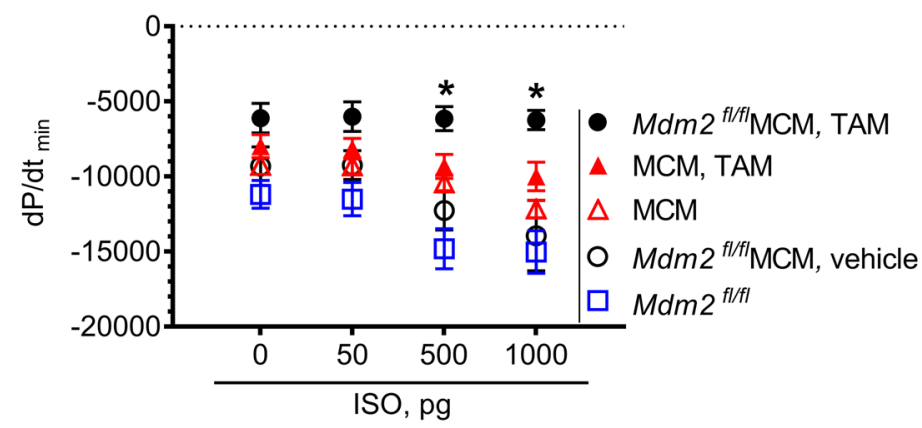

Figure 7. Tamoxifen-induced conditional deletion of Mdm2 in the heart causes severe cardiac dysfunction. (A) Representative echocardiograms via M-mode, short-axis imaging, of the same mouse of indicated genotype, before and after tamoxifen (TAM) (see Table 3 for ECHO analyses). (B) Maximal first derivative of $L V$ pressure in anesthetized $M d m 2^{f / f l}(n=$ 14), Mdm $2^{f / f} M C M$ (vehicle, $n=11 ; \operatorname{TAM}, n=3$ ), and MCM (untreated, $n=9$; TAM, $n=12$ ) mice subjected to increasing doses of isoproterenol (ISO). ${ }^{*} P<0.01$ versus vehicle treated; ${ }^{*} P<$ 0.01 versus all, 2 -way ANOVA, Dunnett's test. (C) Minimal first derivative of LV pressure of the aforementioned mice. ${ }^{*} P<0.01$ versus vehicle treated, 2-way ANOVA, Dunnett's test. (D) Cardiac GRK2 expression in Mdm2 $2^{f / f l} / \mathrm{MCM}$, and MCM mice treated \pm TAM for 1 week. (E) Dot plot shows GRK2/GAPDH ratio in each group. ${ }^{* *} P<0.01$ versus all groups, 1 -way ANOVA, Bonferroni posttest.
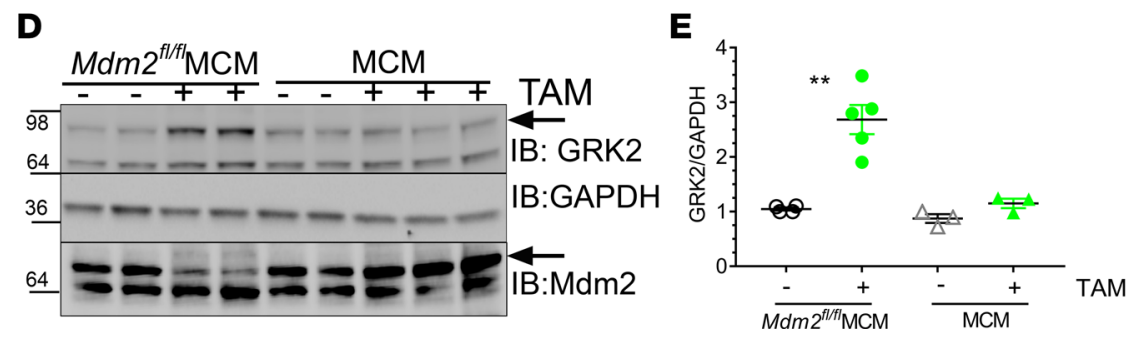

normal cardiac function. Mdm2 may thus serve as a biological rheostat that regulates GRK2-mediated desensitization of $\beta A R$ responsiveness.

In summary, Mdm2 modulates the expression of p53 and GRK2, which are elevated in the failing heart. Mdm2 inhibition, which stabilizes p53 levels, is a main therapeutic strategy for treating a number of cancers. Mdm2 inhibitors that ablate Mdm2-p53 interaction are being used in clinical trials for treating cancer; however, the extent to which these drugs affect overall activity of Mdm2 is unclear (66). Based on our findings, such ongoing efforts of Mdm2 inhibition in cancer therapy would benefit by testing the effects of these compounds on cardiac GRK2 expression and $\beta$ AR signaling.

\section{Methods}

Mice strains. Mdm2/p53-KO (imported from the University of Massachusetts Medical School) and $129(\mathrm{Cg})-M d m 2^{\text {tml.2Mep }}$, strain 01XH9 (common name, Mdm2-flox, National Cancer Institute mouse 

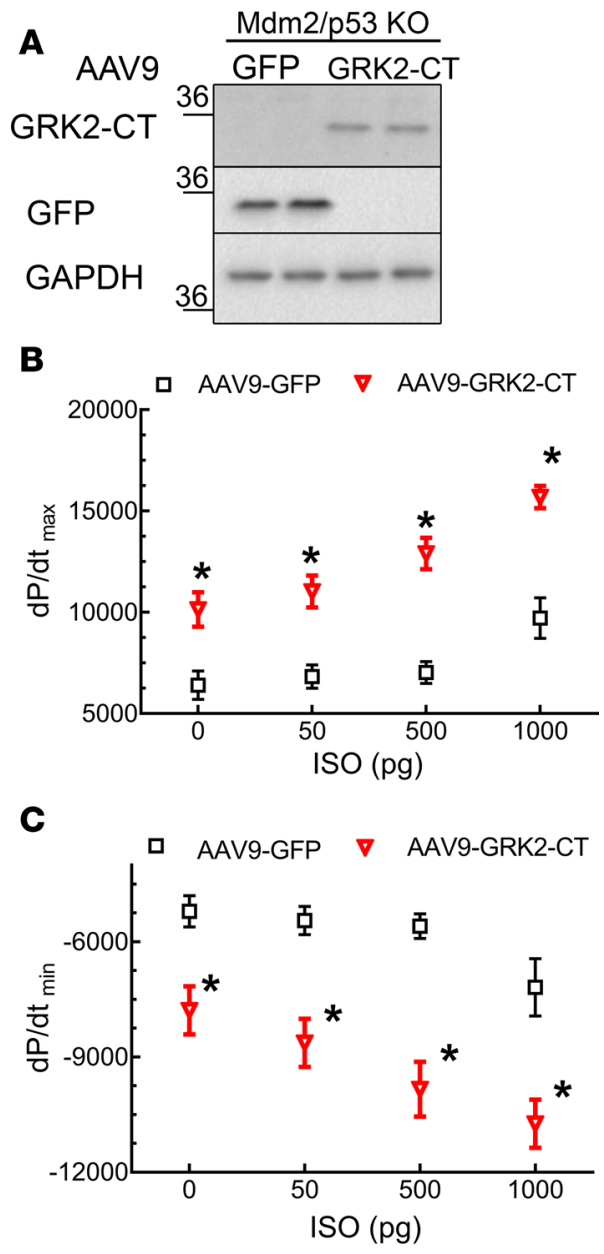

Figure 8. AAV9-GRIK2-CT gene delivery rescues the $\beta A R$ responsiveness in Mdm2/p53-KO mice. (A) Lysates prepared from LVs of Mdm2/p53-KO mice injected with either AAV9-GFP or AAV9GRK2-CT were serially immunoblotted for GRK2-CT, GFP, and GAPDH. Hemodynamic parameters measured in anesthetized mice were (B) maximal first derivative of LV pressure and (C) minimal first derivative of LV pressure. $n=6$ (AAV9-GFP) and $n=11$ (AAV9-GRK2-CT). ${ }^{*} P<0.01,2$-way ANOVA, Bonferroni posttest. ISO, isoproterenol.

repository) have been described previously $(26,67)$. B6129SF1/J (The Jackson Laboratory) mice were used as control WT mice for $\mathrm{Mdm} 2 / \mathrm{p} 53-\mathrm{KO}$ because this compound double KO is sustained and inbred in a mixed 129/BL6 background. The $\alpha$-MHCMerCreMer (MCM) was purchased from the Jackson Laboratory (stock 005657). $M d m 2^{f / f f} \mathrm{MCM}$ was generated by crossbreeding 2 parental strains, namely, $M d m 2^{f l / f l}$ and MCM. Mdm $2^{f / f} \mathrm{MCM}, M d m 2^{f /+} \mathrm{MCM}$, and MCM littermates were used in experimental cohorts. MCM pups obtained by crossbreeding MCM with C57/BL6 were used in some experiments, when age- and gender-matched littermates were unavailable to complete an experimental cohort.

Experimental design. All mouse physiology experiments were carried out with the help of expertise and resources available within the Duke Cardiovascular Research Center Core Facility and according to published protocols $(5,68,69)$. Mice that died after receiving anesthesia or became hypotensive during the course of the procedure, suggesting a surgical complication, were excluded. Investigators blinded to specimen identity accomplished data acquisition and analyses. The number of mice and experimental replicates are indicated in respective figure legends.

Reagents. Antibodies were purchased from the following sources: GAPDH (catalog 3683 ) and K48 linkage-specific polyubiquitin (catalog 12805), p53 (catalog 32532), caspase 3 (catalog 9665), Cell Signaling Technology; GRK2 (catalog sc-562), GRK2/3 (catalog sc-8329), GFP (catalog sc-53882), phospholamban (catalog sc-393990), PKAa (catalog sc-903), normal rabbit IgG (catalog sc-2027), Santa Cruz Biotechnology; Mdm2 (catalog ab87134), Abcam Inc. Horseradish peroxidase-conjugated secondary antibodies were from Jackson ImmunoResearch Inc. or Rockland Immunochemicals. Agarose-TUBEs (UM402) and uncoupled agarose (UM400) were purchased from LifeSensors, Inc. Protein G Plus/Protein A-Agarose was obtained from Calbiochem. (-)-Isoproterenol (+)-bitartarate (catalog I2760) was purchased from Sigma-Aldrich. Forskolin (catalog 11018) was obtained from Cayman Chemicals.

Murine transthoracic echocardiography. Noninvasive echocardiography studies were performed on awake 3- to 4-month-old mice with a Vevo 2100 high-resolution in vivo imaging system (VisualSonics). M-mode echocardiography acquired from parasternal short axis view of the heart was used for quantification of LV wall thickness, chamber dimension, and cardiac contractility. Aortic ejection time (AET) was measured via
Figure 9. Mdm2 acts as a rheostat for GRK2-mediated desensitization of $\beta 1 A R$ signaling in the heart. In WT cardiomyocytes, catecholamine binding triggers $\beta 1 A R$ signaling to CAMP and elicits cardiac contractility. Agonist activation promotes GRK2 phosphorylation of the $\beta 1 A R$, leading to desensitization. However, GRK2 activity and availability is limited by Mdm2, which modifies GRK2 with lysine-48 polyubiquitin and promotes its proteasomal degradation. When Mdm2 is deleted, GRK2 levels are elevated because of impaired ubiquitin-dependent degradation; this temporally locks available $\beta 1 A R s$ in a desensitized state, resulting in a blunted contractile response with catecholamine stimulation.
Wild Type cardiomyocyte Mdm2/p53 KO cardiomyocyte
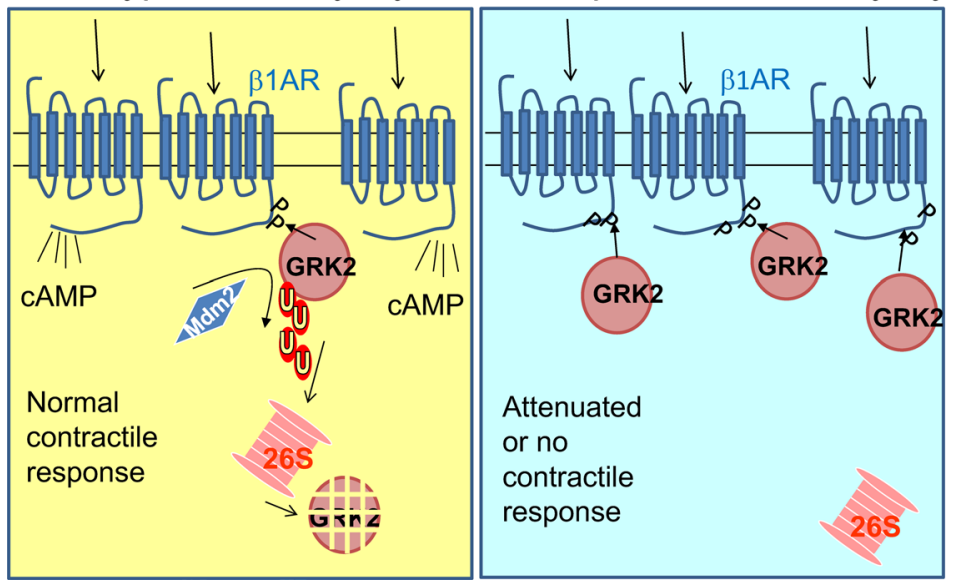
pulse-wave Doppler mode (PWD). All echocardiography measurements were performed according to the guidelines of the American Society of Echocardiography. Image and data analyses were carried out with the Vevo 2100 Imaging System by an examiner blinded to mouse genotype.

Cardiac morphological and histological examinations. Gross heart morphology was assessed on 3- to 4-month-old mice. Freshly isolated hearts were fixed in 10\% formalin and hematoxylin and eosin or Masson's trichrome staining were performed by the Duke Pathology Core facility. Slides were visualized with a Zeiss Axio Imager wide-field fluorescence microscope at $\times 20$ magnification. Image processing and stitching were performed using the software ZEN version 2.3 (Carl Zeiss Microscopy). Image quantification was performed using NIH ImageJ.

Hemodynamic measurements. Mice (3 to 4 months old) were anesthetized by intraperitoneal injection of a mixture of ketamine $(100 \mathrm{mg} / \mathrm{kg})$ and xylazine $(2.5 \mathrm{mg} / \mathrm{kg})$. A 1.4-Fr pressure-conductance catheter (Millar Instruments) was inserted into the animal's LV via the right carotid artery. Hemodynamic measurements were obtained at baseline and 45 to 60 seconds after infusion of incremental doses of isoproterenol given intravenously as reported before $(5,70)$. For experiments involving AAV gene delivery, hemodynamic measurements were performed 21 days after virus infection. AAV9 experiments were performed 4 independent times and 1 uninjected WT control mouse was also phenotyped for $\beta$ AR-induced cardiac contractility in parallel with each AAV9 cohort.

$P$-V loop analysis. In vivo pressure-volume $(\mathrm{P}-\mathrm{V})$ analysis was performed in anesthetized mice as previously described (5). Briefly, after bilateral vagotomy, the chest was opened and the pericardium was dissected to expose the heart. A 7-0-suture ligature was placed around the transverse aorta to manipulate loading conditions. A 1.4-Fr pressure-conductance catheter was inserted retro-aortically into the LV to record hemodynamics. Baseline hemodynamic parameters were obtained once the catheter recordings had achieved steady state, usually 3 to 5 minutes following conductance-catheter placement. Loadindependent parameters were established by generating a series of P-V loops with decreasing preload through transient constriction of the inferior vena cava. Subsequently, parallel conductance (Vp) was determined by $10-\mu 1$ injection of $15 \%$ saline into the right jugular vein to establish the parallel conductance of the blood pool. The derived Vp was used to correct the P-V loop data. Data were recorded digitally at $1,000 \mathrm{~Hz}$ and analyzed with P-V analysis software (PVAN data analysis software version 3.3; Millar Instruments) as previously described (5).

Electrophysiological recordings. Patch-clamp experiments were performed in freshly isolated cardiac myocytes to record currents in the whole-cell voltage-clamp mode using a MultiClamp-700A amplifier with Digidata 1322A interface and analyzed with pCLAMP software (Axon Instruments) as described previously (71) with some modifications. The patch pipettes had a resistance of 1-3 M $\Omega$ when filled with pipette solution contained (in mM): 140 Cs-aspartate, $1 \mathrm{MgCl}_{2}, 5 \mathrm{HEPES}, 10$ EGTA, $3 \mathrm{Na}_{2} \mathrm{ATP}, 0.4$ GTP, pH 7.2 (with $\mathrm{CsOH}$ ). The external solution was composed of (in $\mathrm{mM}$ ) 137 tetraethylammonium chloride (TEA-Cl), $1.8 \mathrm{CaCl}_{2}, 1.2 \mathrm{MgSO}_{4}, 5.4 \mathrm{CsCl}, 10 \mathrm{HEPES}, 15$ glucose, pH 7.4 (with TEA-OH). Three millimolar 4-aminopyridine was added to the external solution before measurements were conducted. $\mathrm{I}_{\text {ca. } \mathrm{L}}$ was elicited by a test potential of $10 \mathrm{mV}$ for $250 \mathrm{~ms}$ from a holding potential of $-40 \mathrm{mV}$. The current-voltage relationship was derived from currents induced by $250 \mathrm{~ms}$ test potentials from $-40 \mathrm{mV}$ to $60 \mathrm{mV}$ in $10-\mathrm{mV}$ steps from the holding potential $(-40 \mathrm{mV})$. Experiments were performed at room temperature $\left(20^{\circ} \mathrm{C}-22^{\circ} \mathrm{C}\right.$ ) with a sample rate of $10 \mathrm{kHz}$ (filtered at $4 \mathrm{kHz}$ ). Currents were normalized by membrane capacitance.

Immunoprecipitation and immunoblotting. Freshly isolated mouse ventricles were snap-frozen in liquid nitrogen; subsequently they were solubilized in an ice-cold lysis buffer containing $20 \mathrm{mM}$ Tris-Cl (pH 7.4), $137 \mathrm{mM} \mathrm{NaCl}, 20 \%$ (v/v) glycerol, and 1\% (v/v) IGEPAL CA-630, supplemented with phosphatase and protease inhibitors ( $1 \mathrm{mM}$ sodium orthovanadate, $10 \mathrm{mM}$ sodium fluoride, $10 \mathrm{mM}$ phenylmethylsulfonyl fluoride, $5 \mu \mathrm{g} / \mathrm{ml}$ leupeptin, $5 \mu \mathrm{g} / \mathrm{ml}$ aprotinin, $1 \mu \mathrm{g} / \mathrm{ml}$ phosphatase inhibitor cocktail 2 (P5726), and 1 $\mu \mathrm{g} / \mathrm{ml}$ phosphatase inhibitor cocktail 3 (P0044); all were from Sigma-Aldrich. Tissue lysates were centrifuged at $35,000 \mathrm{~g}$ for 30 minutes at $4^{\circ} \mathrm{C}$ and the supernatant collected. Proteins ( 1 to $2 \mathrm{mg}$ ) were immunoprecipitated using GRK2 antibody (Santa Cruz Biotechnology, catalog sc-562) or normal IgG with Protein G Plus/Protein A-Agarose beads. After overnight end-over-end rotation at $4^{\circ} \mathrm{C}$, immune complexes were washed 3 times with lysis buffer and eluted in $2 \times$ SDS-PAGE sample buffer. Immunoprecipitated samples were separated side by side with $20 \mu \mathrm{g}$ of their corresponding lysates in a $4 \%$ to $12 \%$ gradient polyacrylamide Tris-glycine gel and later transferred onto nitrocellulose membranes. Membranes were blocked and 
probed in 5\% (w/v) dried skim milk powder dissolved in 2\% (v/v) Tween 20, $10 \mathrm{mM}$ Tris- $\mathrm{Cl}$, ( $\mathrm{pH} 8.0)$, and $150 \mathrm{mM} \mathrm{NaCl}$ (TTBS). Enhanced chemiluminescence (SuperSignal West Pico reagent, Pierce) was used for protein detection. Immunoblots were scanned and quantified using a charge-coupled device camera system and Image-Lab software (Bio-Rad).

Polyubiquitinated protein pulldown. High-affinity pulldown of polyubiquitin conjugates was performed using TUBEs according to the manufacturer's protocol. Protein lysates ( 1 to $2 \mathrm{mg}$ ) from mouse ventricles were processed similarly to those in the immunoprecipitation experiments except that the ubiquitin binding complexes were washed in TTBS prior to their elution. Eluted samples were resolved concurrently with 20 $\mu \mathrm{g}$ of their cognate lysates in $4 \%$ to $20 \%$ gradient polyacrylamide gels.

cAMP measurements. Hearts were harvested from 3- to 4-month-old mice 15 minutes after intraperitoneal injection of isoproterenol ( $1 \mathrm{ng} / \mathrm{g}$ body weight) or saline. Total cAMP levels were measured in triplicate using a Direct cAMP ELISA kit (ADI-900-066) from Enzo Life Sciences according to the manufacturer's instructions.

Membrane isolation from mouse hearts. LVs isolated from WT and Mdm2/p53-KO mice were lysed in ice-cold homogenization buffer containing $25 \mathrm{mM}$ Tris- $\mathrm{Cl}$ (pH 7.4), $5 \mathrm{mM}$ EDTA (pH 8.0), $5 \mu \mathrm{g} / \mathrm{ml}$ leupeptin, and $10 \mu \mathrm{g} / \mathrm{ml}$ aprotinin. The cardiac homogenates were centrifuged at $500 \mathrm{~g}$ for 5 minutes at $4^{\circ} \mathrm{C}$ to remove debris followed by a high-speed centrifugation of the supernatant $\left(35,000 \mathrm{~g}\right.$ for 30 minutes at $\left.4^{\circ} \mathrm{C}\right)$ to precipitate membranes. Membrane fractions were stored at $-80^{\circ} \mathrm{C}$ in resuspension buffer containing 75 mM Tris-Cl, (pH 7.4), 2 mM EDTA ( $\mathrm{pH} 8.0$ ), $12.5 \mathrm{mM} \mathrm{MgCl}, 5 \mu \mathrm{g} / \mathrm{ml}$ leupeptin, and $10 \mu \mathrm{g} / \mathrm{ml}$ aprotinin.

Radioligand binding assays. $\beta \mathrm{AR}$ expression in LVs of $\mathrm{WT}$ and $\mathrm{Mdm} 2 / \mathrm{p} 53-\mathrm{KO}$ mice were determined via radioligand binding assays as reported before $(34,35)$. All membranes were diluted to a concentration of $0.5 \mathrm{mg} / \mathrm{ml}$ in ice-cold binding assay buffer containing $50 \mathrm{mM}$ Tris- $\mathrm{Cl}(\mathrm{pH} 7.4), 2 \mathrm{mM}$ EDTA (pH 8.0), $12.5 \mathrm{mM} \mathrm{MgCl}_{2}$, and $180 \mu \mathrm{g} / \mathrm{ml} \mathrm{L}$-ascorbic acid. Serial dilutions of the $\beta A R$ antagonist ICI- 118551 $(0.316 \mathrm{pM}$ to $3.16 \mu \mathrm{M})$ were added in duplicate to $50 \mu \mathrm{g}$ of ventricular membranes; $60 \mathrm{pM}\left[{ }^{125} \mathrm{I}\right](-)$-iodocyanopindolol $\left(\left[{ }^{125} \mathrm{I}\right] \mathrm{CYP}\right)$ was added to all samples, whereas $20 \mu \mathrm{M}$ of the antagonist propranolol was used to determine nonspecific binding. For saturation binding assays 400 to $500 \mathrm{pM}\left[{ }^{125} \mathrm{I}\right] \mathrm{CYP}$ and 500 nM CGP-20712A ( $\beta 1 \mathrm{AR}$-specific) were used to derive total $\beta \mathrm{ARs}$ and $\beta 1$ and $\beta 2$ subtypes, and $20 \mu \mathrm{M}$ propranolol was used to define nonspecific binding. The membrane samples were incubated at room temperature for 90 minutes, and then harvested onto Whatman GF/B glass fiber filters using a Brandel harvester and washed in ice-cold washing buffer (50 mM Tris- $\mathrm{Cl}$ [pH 7.4], 2 mM EDTA [pH 8.0], 12.5 $\mathrm{mM} \mathrm{MgCl}_{2}$ ). Bound radioactivity was measured with a Packard Cobra gamma counter. Data analysis, normalization, and curve fitting were carried out as reported before $(34,35)$.

Production and gene delivery of recombinant AAVs. A cDNA encoding murine Mdm2 was cloned into the vector pTRCMV and AAV9 serotype viruses were produced as per published protocols by a triple-transfection method that introduces pTRCMV-Mdm2, pXR9, and PXX680 in HEK-293 cells (72, 73). The virus titer was determined by dot-blot hybridization. AAV9 encoding Mdm2, GFP, or GRK2-CT was purified and used in our experiments. For Mdm2 and GRK2-CT gene delivery, $2 \times 10^{10}$ and $1 \times 10^{11}$ virus particles were used, respectively, which were injected in a total volume of $80-100 \mu$ into the retro-orbital venous sinus of 8- to 10-week-old mice, under isoflurane anesthesia. Control GFP virus was used at equivalent amounts of particles in each experimental cohort. Twenty-one days after AAV9 injections, cardiac function and $\beta A R$ responsiveness were assessed by hemodynamics.

Statistics. Data are averaged from at least 3 independent experiments and expressed as the mean \pm SEM. A 2-tailed Mann-Whitney test or Student's $t$ test was used to determine differences between WT and $\mathrm{Mdm} 2 / \mathrm{p} 53-\mathrm{KO}$ samples, whereas 2-way ANOVA wa s used for hemodynamic assessments under basal conditions and incremental doses of isoproterenol injections. For all analyses, $P$ less than 0.05 was considered significant. Statistical analyses were done using Prism 6 software (GraphPad, Inc.).

Study approval. All animal experiments were performed in accordance with protocols approved by the Duke University Institutional Animal Care and Use Committee.

\section{Author contributions}

PYJC, SMWY, DA, WJK, HAR, and SKS designed the experiments. PYJC, SMWY, RPK, LM, RTS, ZSZ, LB, and SKS performed the experiments. PYJC, SMWY, DA, RPK, LM, RTS, JAS, and SKS analyzed the data. SNJ, DEB, and WJK provided key reagents. PYJC, SMWY, DA, and SKS wrote the manuscript. 


\section{Acknowledgments}

We acknowledge support from the NIH (HL080525 and HL118369 to SKS; HL125905 to DA; HL56687 and P01 HL75443 to HAR), and 15GRNT25550051 from the American Heart Association (to SKS). We also acknowledge support from the Mandel Center for Hypertension and Atherosclerosis Research and the Duke O’Brien Center for Kidney Research (NIH/NIDDK, award number P30-DK096493).

Address correspondence to: Sudha K. Shenoy, Duke University Medical Center, Rm 412, SANDS Bldg., P.O. Box 103204, 303 Research Drive, Durham, North Carolina 27710, USA. Phone: 919.681.5061; Email: skshenoy@dm.duke.edu.

1. Rockman HA, Koch WJ, Lefkowitz RJ. Seven-transmembrane-spanning receptors and heart function. Nature. 2002;415(6868):206-212.

2. Rohrer DK, Kobilka BK. Insights from in vivo modification of adrenergic receptor gene expression. Annu Rev Pharmacol Toxicol. 1998;38:351-373.

3. Bristow MR, et al. Beta 1- and beta 2-adrenergic-receptor subpopulations in nonfailing and failing human ventricular myocardium: coupling of both receptor subtypes to muscle contraction and selective beta 1-receptor down-regulation in heart failure. Circ Res. 1986;59(3):297-309.

4. Myagmar BE, et al. Adrenergic receptors in individual ventricular myocytes: the $\beta-1$ and $\alpha-1 \mathrm{~B}$ are in all cells, the $\alpha-1 \mathrm{~A}$ is in a subpopulation, and the $\beta-2$ and $\beta-3$ are mostly absent. Circ Res. 2017;120(7):1103-1115.

5. Yoo B, et al. $\beta 1$-Adrenergic receptors stimulate cardiac contractility and CaMKII activation in vivo and enhance cardiac dysfunction following myocardial infarction. Am J Physiol Heart Circ Physiol. 2009;297(4):H1377-H1386.

6. Woo AY, Xiao RP. $\beta$-Adrenergic receptor subtype signaling in heart: from bench to bedside. Acta Pharmacol Sin. 2012;33(3):335-341.

7. Lefkowitz RJ, Shenoy SK. Transduction of receptor signals by beta-arrestins. Science. 2005;308(5721):512-517.

8. DeWire SM, Ahn S, Lefkowitz RJ, Shenoy SK. $\beta$-Arrestins and cell signaling. Annu Rev Physiol. 2007;69:483-510.

9. Shenoy SK, McDonald PH, Kohout TA, Lefkowitz RJ. Regulation of receptor fate by ubiquitination of activated $\beta 2$-adrenergic receptor and $\beta$-arrestin. Science. 2001;294(5545):1307-1313.

10. Salcedo A, Mayor F Jr, Penela P. Mdm2 is involved in the ubiquitination and degradation of G-protein-coupled receptor kinase 2. EMBO J. 2006;25(20):4752-4762.

11. Berthouze M, Venkataramanan V, Li Y, Shenoy SK. The deubiquitinases USP33 and USP20 coordinate $\beta 2$ adrenergic receptor recycling and resensitization. EMBO J. 2009;28(12):1684-1696.

12. Xiao K, Shenoy SK. $\beta 2$-Adrenergic receptor lysosomal trafficking is regulated by ubiquitination of lysyl residues in two distinct receptor domains. J Biol Chem. 2011;286(14):12785-12795.

13. Kommaddi RP, Jean-Charles PY, Shenoy SK. Phosphorylation of the deubiquitinase USP20 by protein kinase A regulates post-endocytic trafficking of $\beta 2$ adrenergic receptors to autophagosomes during physiological stress. J Biol Chem. 2015;290(14):8888-8903.

14. Han SO, et al. MARCH2 promotes endocytosis and lysosomal sorting of carvedilol-bound $\beta(2)$-adrenergic receptors. $J$ Cell Biol. 2012;199(5):817-830.

15. Han SO, Kommaddi RP, Shenoy SK. Distinct roles for $\beta$-arrestin2 and arrestin-domain-containing proteins in $\beta 2$ adrenergic receptor trafficking. EMBO Rep. 2013;14(2):164-171.

16. Shenoy SK, Xiao K, Venkataramanan V, Snyder PM, Freedman NJ, Weissman AM. Nedd4 mediates agonist-dependent ubiquitination, lysosomal targeting, and degradation of the $\beta 2$-adrenergic receptor. J Biol Chem. 2008;283(32):22166-22176.

17. Shenoy SK, et al. $\beta$-Arrestin-dependent signaling and trafficking of 7-transmembrane receptors is reciprocally regulated by the deubiquitinase USP33 and the E3 ligase Mdm2. Proc Natl Acad Sci U S A. 2009;106(16):6650-6655.

18. Shenoy SK, et al. Ubiquitination of $\beta$-arrestin links seven-transmembrane receptor endocytosis and ERK activation. $J$ Biol Chem. 2007;282(40):29549-29562.

19. Penela P, Ruiz-Gómez A, Castaño JG, Mayor F. Degradation of the G protein-coupled receptor kinase 2 by the proteasome pathway. J Biol Chem. 1998;273(52):35238-35244.

20. Gannon HS, Jones SN. Using mouse models to explore MDM-p53 signaling in development, cell growth, and tumorigenesis. Genes Cancer. 2012;3(3-4):209-218.

21. Fang S, Jensen JP, Ludwig RL, Vousden KH, Weissman AM. Mdm2 is a RING finger-dependent ubiquitin protein ligase for itself and p53. J Biol Chem. 2000;275(12):8945-8951.

22. Freedman DA, Wu L, Levine AJ. Functions of the MDM2 oncoprotein. Cell Mol Life Sci. 1999;55(1):96-107.

23. Honda R, Tanaka H, Yasuda H. Oncoprotein MDM2 is a ubiquitin ligase E3 for tumor suppressor p53. FEBS Lett. 1997;420(1):25-27.

24. Montes de Oca Luna R, Wagner DS, Lozano G. Rescue of early embryonic lethality in mdm2-deficient mice by deletion of p53. Nature. 1995;378(6553):203-206.

25. Jones SN, Roe AE, Donehower LA, Bradley A. Rescue of embryonic lethality in Mdm2-deficient mice by absence of p53. Nature. 1995;378(6553):206-208.

26. Jones SN, Sands AT, Hancock AR, et al. The tumorigenic potential and cell growth characteristics of p53-deficient cells are equivalent in the presence or absence of Mdm2. Proc Natl Acad Sci U S A. 1996;93(24):14106-14111.

27. Grier JD, Xiong S, Elizondo-Fraire AC, Parant JM, Lozano G. Tissue-specific differences of p53 inhibition by Mdm2 and Mdm4. Mol Cell Biol. 2006;26(1):192-198.

28. Inagaki K, et al. Robust systemic transduction with AAV9 vectors in mice: efficient global cardiac gene transfer superior to that of AAV8. Mol Ther. 2006;14(1):45-53. 
29. Pacak CA, et al. Recombinant adeno-associated virus serotype 9 leads to preferential cardiac transduction in vivo. Circ Res. 2006;99(4):e3-e9.

30. Bish LT, et al. Adeno-associated virus (AAV) serotype 9 provides global cardiac gene transfer superior to AAV1, AAV6, AAV7, and AAV8 in the mouse and rat. Hum Gene Ther. 2008;19(12):1359-1368.

31. Miyagi N, et al. Efficient and durable gene transfer to transplanted heart using adeno-associated virus 9 vector. $J$ Heart Lung Transplant. 2008;27(5):554-560.

32. Pleger ST, et al. Cardiac AAV9-S100A1 gene therapy rescues post-ischemic heart failure in a preclinical large animal model. $S c i$ Transl Med. 2011;3(92):92ra64.

33. Rohrer DK, et al. Targeted disruption of the mouse beta1-adrenergic receptor gene: developmental and cardiovascular effects. Proc Natl Acad Sci U S A. 1996;93(14):7375-7380.

34. Hara MR, et al. A stress response pathway regulates DNA damage through $\beta 2$-adrenoreceptors and $\beta$-arrestin-1. Nature 2011;477(7364):349-353.

35. Hegde A, Strachan RT, Walker JK. Quantification of beta adrenergic receptor subtypes in $\beta$-arrestin knockout mouse airways. PLoS One. 2015;10(2):e0116458.

36. Girnita L, et al. $\beta$-Arrestin is crucial for ubiquitination and down-regulation of the insulin-like growth factor-1 receptor by acting as adaptor for the MDM2 E3 ligase. J Biol Chem. 2005;280(26):24412-24419.

37. Jean-Charles PY, Rajiv V, Shenoy SK. Ubiquitin-related roles of $\beta$-arrestins in endocytic trafficking and signal transduction. $J$ Cell Physiol. 2016;231(10):2071-2080.

38. Conner DA, et al. $\beta$-Arrestin1 knockout mice appear normal but demonstrate altered cardiac responses to $\beta$-adrenergic stimulation. Circ Res. 1997;81(6):1021-1026.

39. Matkovich SJ, et al. Cardiac-specific ablation of G-protein receptor kinase 2 redefines its roles in heart development and B-adrenergic signaling. Circ Res. 2006;99(9):996-1003.

40. Raake PW, et al. G protein-coupled receptor kinase 2 ablation in cardiac myocytes before or after myocardial infarction prevents heart failure. Circ Res. 2008;103(4):413-422.

41. Rockman HA, et al. Control of myocardial contractile function by the level of beta-adrenergic receptor kinase 1 in gene-targeted mice. J Biol Chem. 1998;273(29):18180-18184.

42. Rockman HA, Koch WJ, Milano CA, Lefkowitz RJ. Myocardial beta-adrenergic receptor signaling in vivo: insights from transgenic mice. J Mol Med. 1996;74(9):489-495

43. Grice GL, Nathan JA. The recognition of ubiquitinated proteins by the proteasome. Cell Mol Life Sci. 2016;73(18):3497-3506.

44. Aillet F, Lopitz-Otsoa F, Hjerpe R, Torres-Ramos M, Lang V, Rodriguez MS. Isolation of ubiquitylated proteins using tandem ubiquitin-binding entities. Methods Mol Biol. 2012;832:173-183.

45. Hjerpe R, Aillet F, Lopitz-Otsoa F, Lang V, England P, Rodriguez MS. Efficient protection and isolation of ubiquitylated proteins using tandem ubiquitin-binding entities. EMBO Rep. 2009;10(11):1250-1258

46. Xolalpa W, Mata-Cantero L, Aillet F, Rodriguez MS. Isolation of the ubiquitin-proteome from tumor cell lines and primary cells using TUBEs. Methods Mol Biol. 2016;1449:161-175.

47. Koitabashi N, et al. Avoidance of transient cardiomyopathy in cardiomyocyte-targeted tamoxifen-induced MerCreMer gene deletion models. Circ Res. 2009;105(1):12-15.

48. Liu R, et al. Cardiac-specific deletion of protein phosphatase $1 \beta$ promotes increased myofilament protein phosphorylation and contractile alterations. J Mol Cell Cardiol. 2015;87:204-213.

49. Koch WJ, Rockman HA, Samama P, et al. Cardiac function in mice overexpressing the $\beta$-adrenergic receptor kinase or a $\beta$ ARK inhibitor. Science. 1995;268(5215):1350-1353.

50. Cannavo A, Liccardo D, Koch WJ. Targeting cardiac $\beta$-adrenergic signaling via GRK2 inhibition for heart failure therapy. Front Physiol. 2013;4:264.

51. Schumacher SM, et al. Paroxetine-mediated GRK2 inhibition reverses cardiac dysfunction and remodeling after myocardia infarction. Sci Transl Med. 2015;7(277):277ra31.

52. Toth A, Nickson P, Qin LL, Erhardt P. Differential regulation of cardiomyocyte survival and hypertrophy by MDM2, an E3 ubiquitin ligase. J Biol Chem. 2006;281(6):3679-3689.

53. Sano M, et al. p53-induced inhibition of Hif-1 causes cardiac dysfunction during pressure overload. Nature. 2007;446(7134):444-448.

54. Gogiraju R, et al. Endothelial p53 deletion improves angiogenesis and prevents cardiac fibrosis and heart failure induced by pressure overload in mice. $J$ Am Heart Assoc. 2015;4(2):2

55. Song H, Conte JV Jr, Foster AH, McLaughlin JS, Wei C. Increased p53 protein expression in human failing myocardium. J Heart Lung Transplant. 1999;18(8):744-749.

56. Leri A, et al. Pacing-induced heart failure in dogs enhances the expression of p53 and p53-dependent genes in ventricular myocytes. Circulation. 1998;97(2):194-203.

57. Hall ME, Smith G, Hall JE, Stec DE. Systolic dysfunction in cardiac-specific ligand-inducible MerCreMer transgenic mice. Am J Physiol Heart Circ Physiol. 2011;301(1):H253-H260.

58. Molkentin JD, Robbins J. With great power comes great responsibility: using mouse genetics to study cardiac hypertrophy and failure. J Mol Cell Cardiol. 2009;46(2):130-136.

59. Doetschman T, Azhar M. Cardiac-specific inducible and conditional gene targeting in mice. Circ Res. 2012;110(11):1498-1512.

60. Fridman JS, Lowe SW. Control of apoptosis by p53. Oncogene. 2003;22(56):9030-9040.

61. Schuler M, Bossy-Wetzel E, Goldstein JC, Fitzgerald P, Green DR. p53 induces apoptosis by caspase activation through mitochondrial cytochrome c release. J Biol Chem. 2000;275(10):7337-7342.

62. Penela P. Chapter three - ubiquitination and protein turnover of G-protein-coupled receptor kinases in GPCR signaling and cellular regulation. Prog Mol Biol Transl Sci. 2016;141:85-140.

63. Feldman DS, Elton TS, Sun B, Martin MM, Ziolo MT. Mechanisms of disease: detrimental adrenergic signaling in acute decompensated heart failure. Nat Clin Pract Cardiovasc Med. 2008;5(4):208-218.

64. Agüero J, et al. Myocardial G protein receptor-coupled kinase expression correlates with functional parameters and clinical 
severity in advanced heart failure. J Card Fail. 2012;18(1):53-61.

65. Huang ZM, Gold JI, Koch WJ. G protein-coupled receptor kinases in normal and failing myocardium. Front Biosci (Landmark Ed). 2011;16:3047-3060

66. Zhao Y, Aguilar A, Bernard D, Wang S. Small-molecule inhibitors of the MDM2-p53 protein-protein interaction (MDM2 Inhibitors) in clinical trials for cancer treatment. J Med Chem. 2015;58(3):1038-1052.

67. Mendrysa SM, McElwee MK, Michalowski J, O'Leary KA, Young KM, Perry ME. mdm2 Is critical for inhibition of p53 during lymphopoiesis and the response to ionizing irradiation. Mol Cell Biol. 2003;23(2):462-472.

68. Abraham DM, et al. $\beta$-Arrestin mediates the Frank-Starling mechanism of cardiac contractility. Proc Natl Acad Sci U S A. 2016;113(50):14426-14431.

69. Noma T, et al. $\beta$-Arrestin-mediated $\beta 1$-adrenergic receptor transactivation of the EGFR confers cardioprotection. $J$ Clin Invest. 2007;117(9):2445-2458.

70. Rockman HA, et al. Segregation of atrial-specific and inducible expression of an atrial natriuretic factor transgene in an in vivo murine model of cardiac hypertrophy. Proc Natl Acad Sci U S A. 1991;88(18):8277-8281.

71. Zhang ZS, Cheng HJ, Ukai T, Tachibana H, Cheng CP. Enhanced cardiac L-type calcium current response to $\beta 2$-adrenergic stimulation in heart failure. J Pharmacol Exp Ther. 2001;298(1):188-196.

72. Zincarelli C, Soltys S, Rengo G, Rabinowitz JE. Analysis of AAV serotypes 1-9 mediated gene expression and tropism in mice after systemic injection. Mol Ther. 2008;16(6):1073-1080.

73. Grieger JC, Choi VW, Samulski RJ. Production and characterization of adeno-associated viral vectors. Nat Protoc. 2006;1(3):1412-1428. 